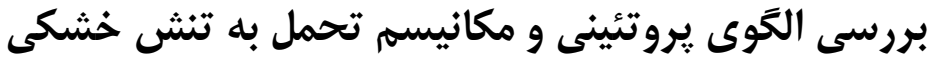

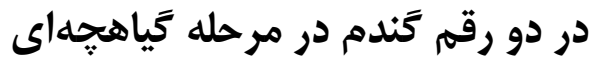 \\ محمدرضا نقوى ، محمود تورجى ${ }^{2}$
}

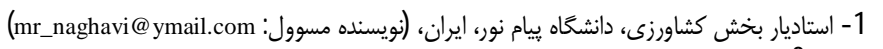

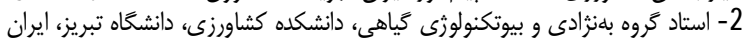

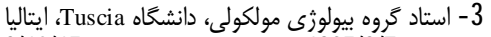

تاريخ دريافت: 1395/2/7

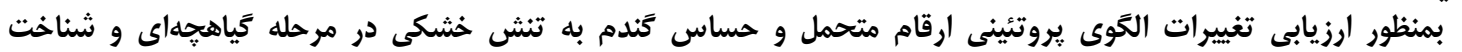

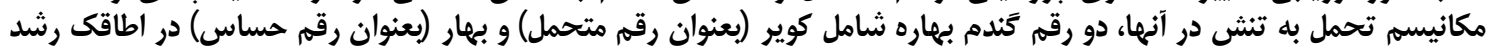

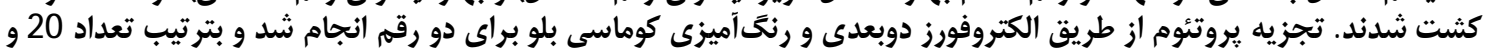

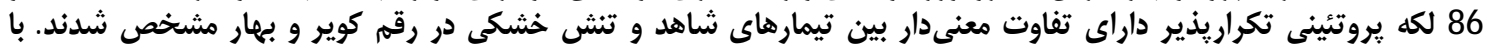

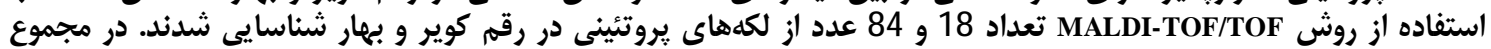

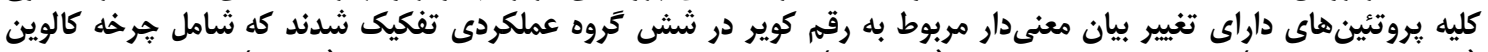

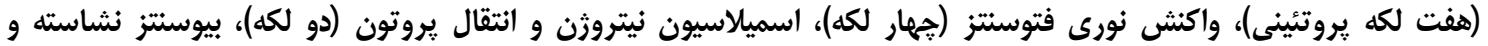

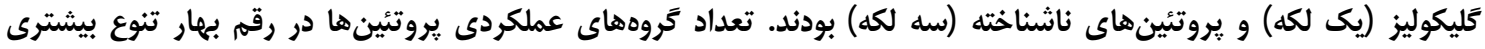

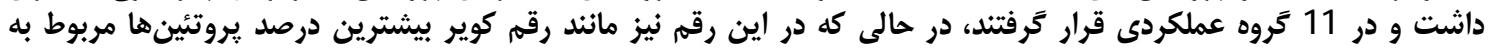

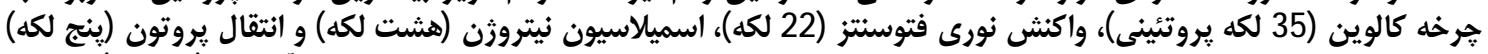

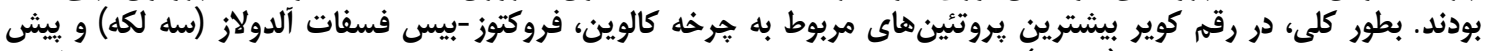

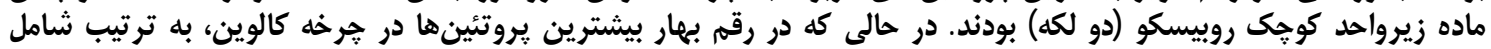

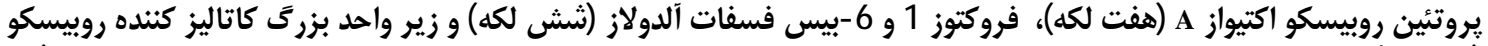

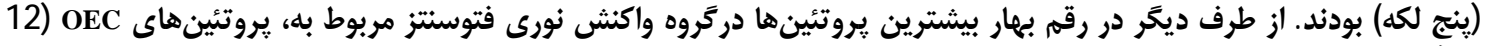

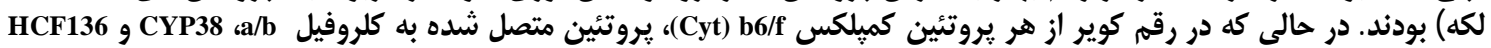

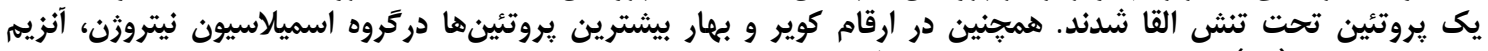

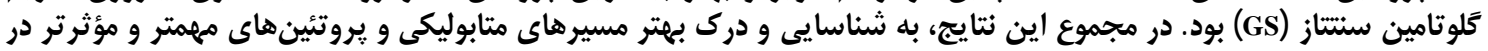

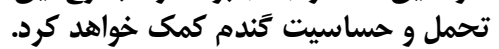

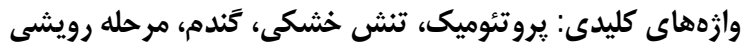

همكاران (5) اولين كسانى بودند كه براى تجزيه و تحرئ تحليل

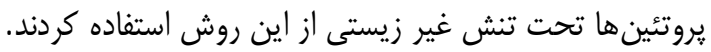

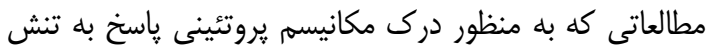

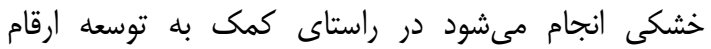

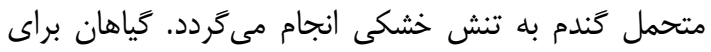

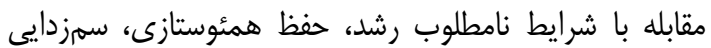

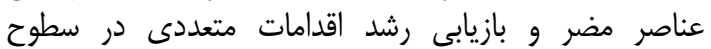

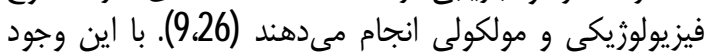

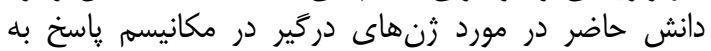

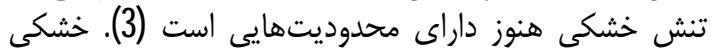

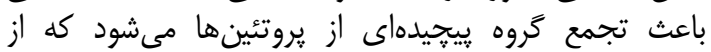

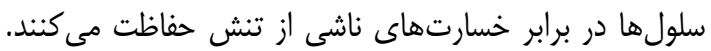

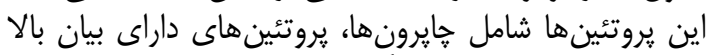

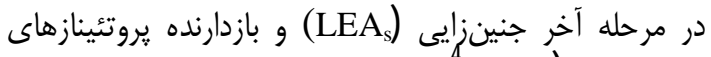

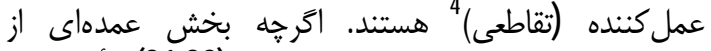
يروتئينهاى دركير هنوز ناشناخته هستند (3132). تأثير انواع

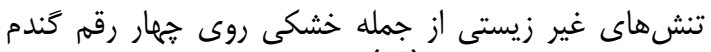

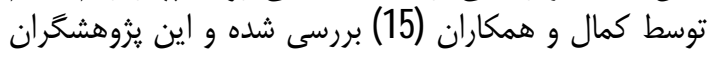

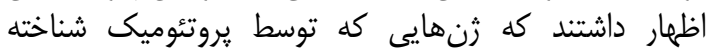
مىشوند مى تواند براى انتخاب از طريق نشانكر يا برنامههاى
مقدمه - مق

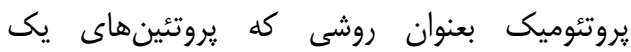

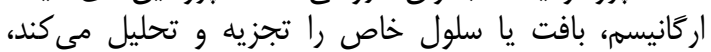

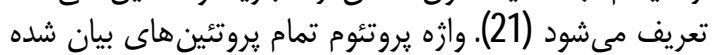

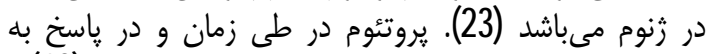

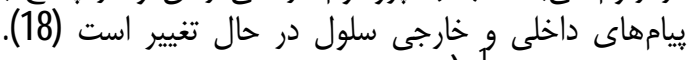

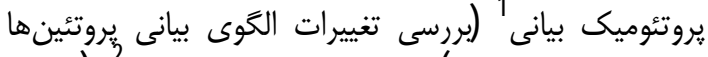

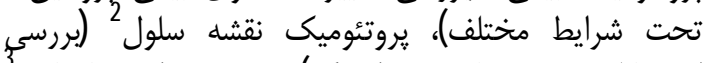

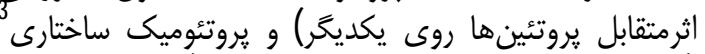

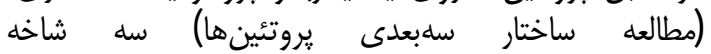

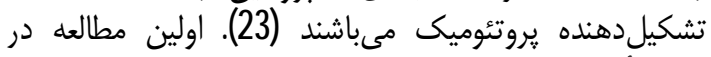

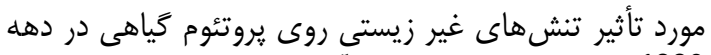

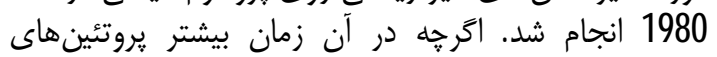

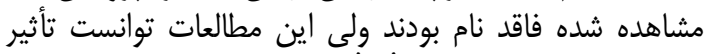

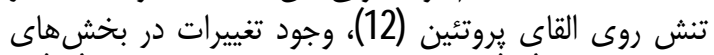

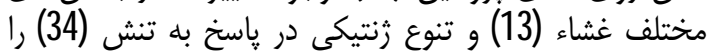

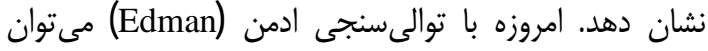

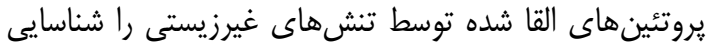

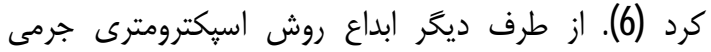

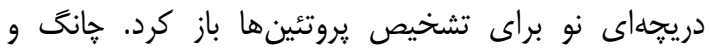


SDS-PAGE كوماسى بلو انجام شد (7).

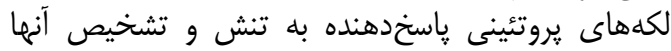

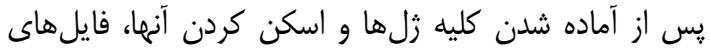

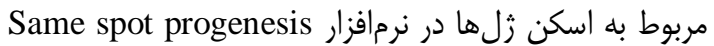

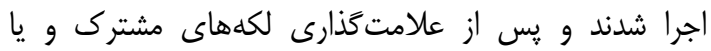

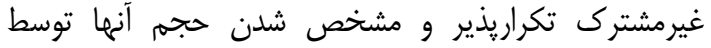

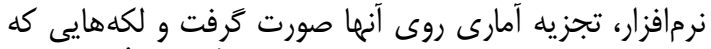

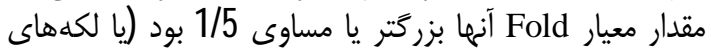

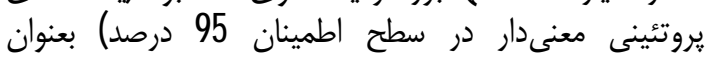

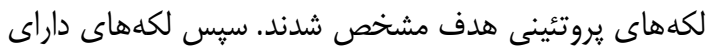

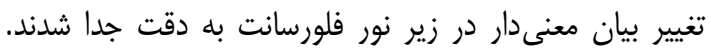

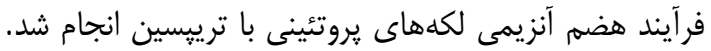

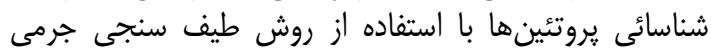

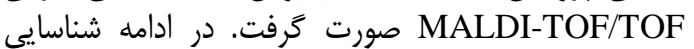

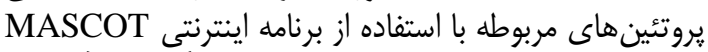

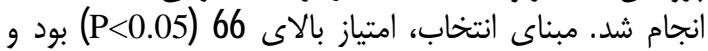

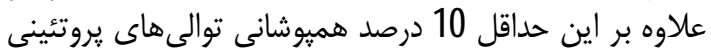

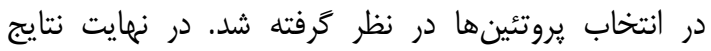

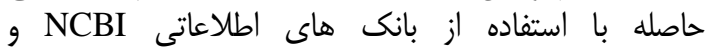
Expasy مورد جستجو و بررسى قرار كرفت. تجزيه و تحليل آمارى

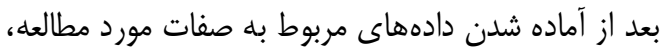

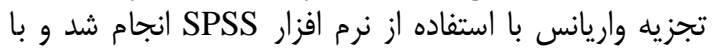
توجه به دو سطح بودن كليه فاكتورهاى آزمايشى، معنى داردار

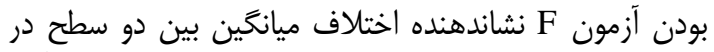

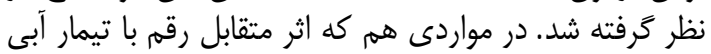

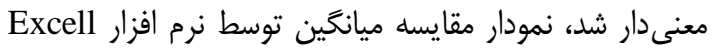

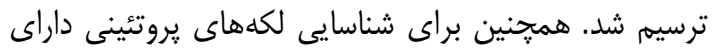

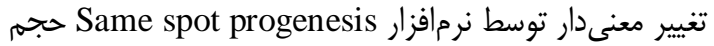

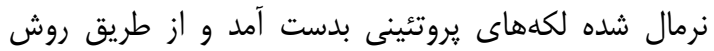
آمارى ANOVA در سطح احتمال \% \$ و و مقايسه ميانكين

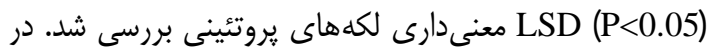

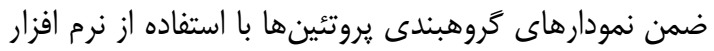
Excell نتايج و بحث كوير و بهار در آزمايشهاى قبلى براى تنش ارتش

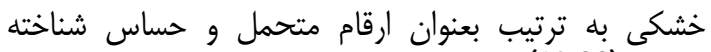

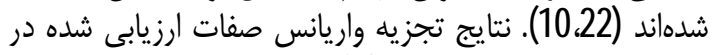

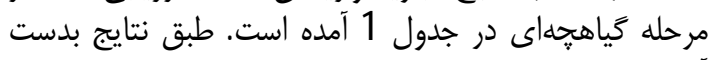

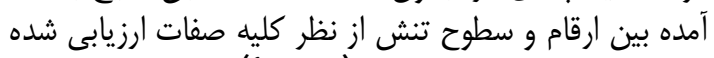

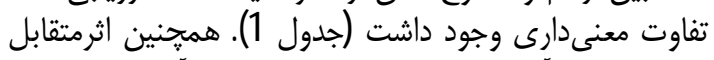

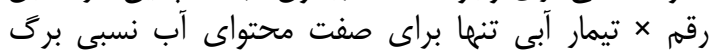

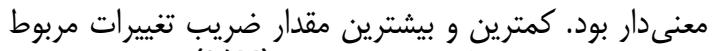

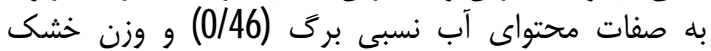

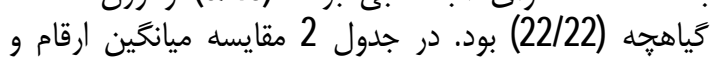

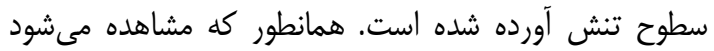

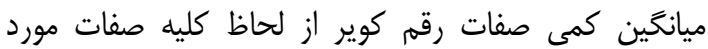

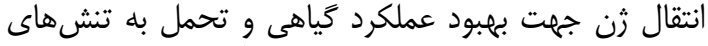

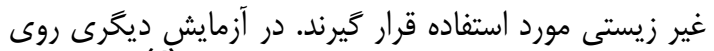

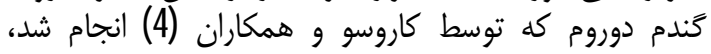

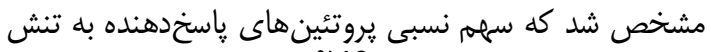

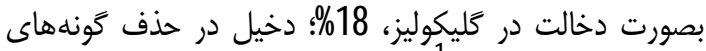

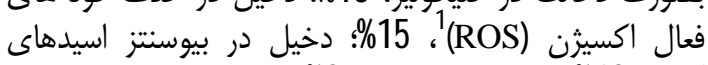

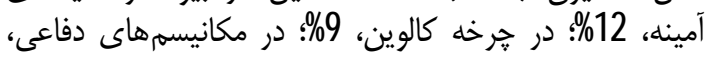

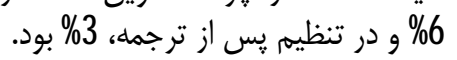

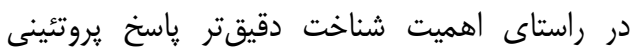

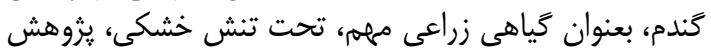

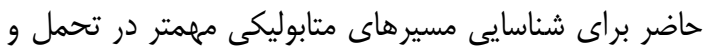
حساسيت كندم تحت تنش خشكى انجام كرديده است.

\section{مواد و روشها

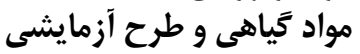

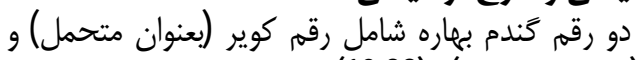

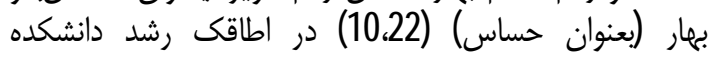

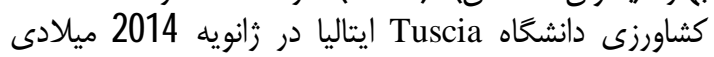

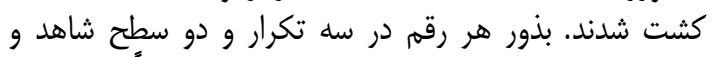

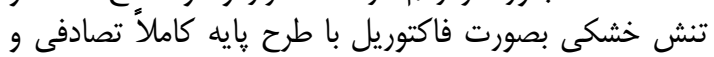

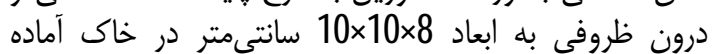
زراعى كشت شدند. در هر واحد آزمايشى 10 عدرد بذر بذر كاشته درانه

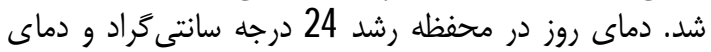

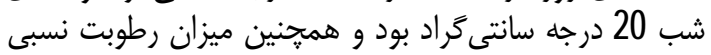

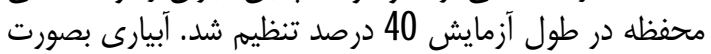

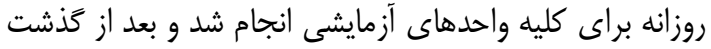

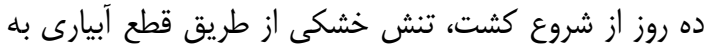

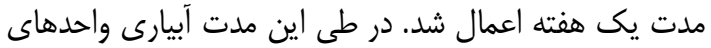

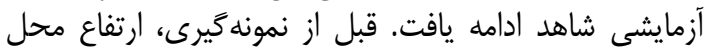

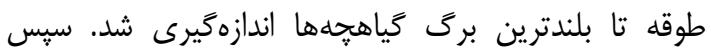

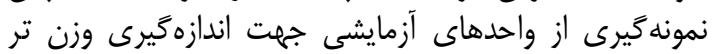

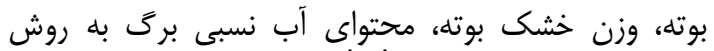

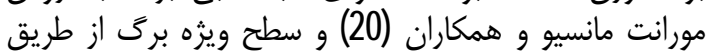

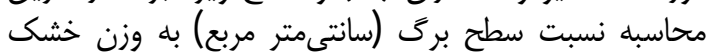

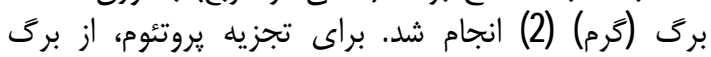

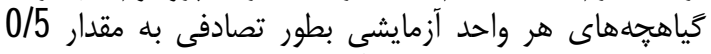

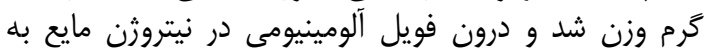

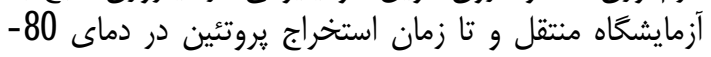

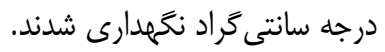

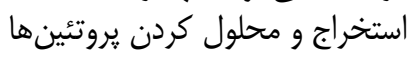

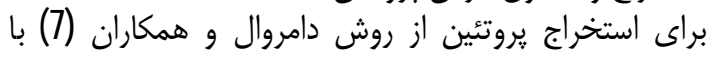

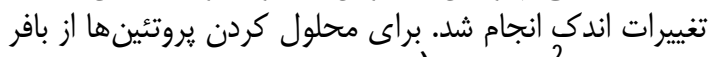

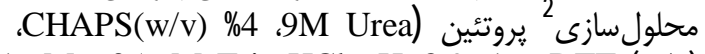
$1 \mathrm{mM} 335 \mathrm{mM}$ Tris HCl pH=8.9، 1\% DTT (w/v) (0.1mM EDTA و استفاده شد (7). براى تعيين PMSF غلظت يروتئين در نمونهها از روش (0) النفاده الكتروفورز دوبعدى و رنغى آميزى خل براى انجام الكتروفورز

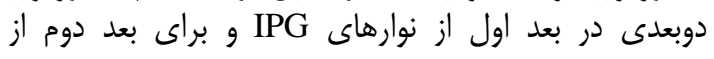


شدن اثر متقابل رقم با تنش، تركيب تيمارى ارقام و سطوح

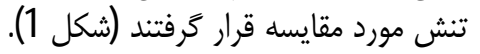

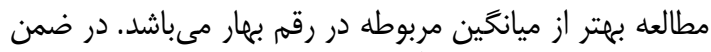

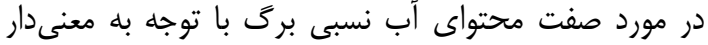

جدول 1 - تجزيه واريانس صفات مورد مطالعه تحت تيمارهاى آبى براى دو رقم كوير و بهار Table 1. Analysis of variance of studied traits under water treatments for Kavir and Bahar cultivars

\begin{tabular}{|c|c|c|c|c|c|c|}
\hline \multicolumn{5}{|c|}{ ميانكين مربعات } & \multirow[b]{2}{*}{ درجه آزادى } & \multirow[b]{2}{*}{ منابع تغييرات } \\
\hline وزن خشى گياهجه & 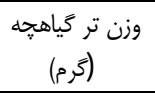 & 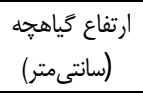 & 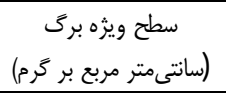 & محتواى آب نسبى بركى & & \\
\hline $\mathrm{C} / 004^{* *}$ & $C / 00 E^{*}$ & $21 / 3 C^{* *}$ & $298=/ 00^{*}$ & $23 / 9 x^{* *}$ & 1 & تيمار آبى \\
\hline C/OOE** & $\left(/ 022^{* *}\right.$ & $1 \equiv / 44^{* * *}$ & $5 / 9\left(27^{* * *}\right.$ & $195 / œ^{* *}$ & 1 & رقم \\
\hline$c / 001$ & $\mathrm{C} / 002$ & $\Xi / 1 C$ & ळะ/T: & $3 / 3 C^{*}$ & 1 & رقم> تيمار آبى \\
\hline C/OOOE & c/011 & $2 / 9$ & $32=/ \propto$ & $C / Q$ & $\varepsilon$ & خطا \\
\hline $2 / 2$ & $7 / 0 \subseteq$ & $7 / 7 C$ & $\mathrm{C} / \mathbb{R}$ & $C / 4 E$ & & ضريب تغييراته| \\
\hline
\end{tabular}

جدول 2- - مقايسه ميانكين سطوح تنش و ارقام كوير و بهار براى صفات مورد مطالعه Table 2. Mean comparison of stress levels and Kavir and Bahar cultivars for studied traits

\begin{tabular}{|c|c|c|c|c|}
\hline وزن خشك كَياهجه (كرم) & وزن تر كَياهجه (َّرم) & ارتفاع كياهجه (سانتى متر) & 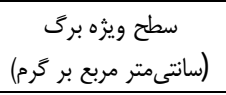 & سطوح تنش \\
\hline Q10 & Q334 & $17 / 15^{a}$ & 15609 & شاهد \\
\hline \multirow[t]{2}{*}{$\alpha 00^{\circ}$} & $0 / 29^{\circ}$ & $14 / 14$ & 187/రో & تيمار آبى \\
\hline & & & & 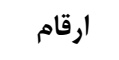 \\
\hline$\alpha 11^{\mathrm{a}}$ & Q/356 & $1670^{\prime}$ & $14989^{\prime}$ & كوير \\
\hline$\alpha 0 \sigma^{\circ}$ & Q/269 & $14 / 59$ & $193 / 8^{b}$ & بهار \\
\hline
\end{tabular}

حروف متفاوت در هر ستون نشاندهنده تفاوت معنىار بر اساس آزمون F مىباشد

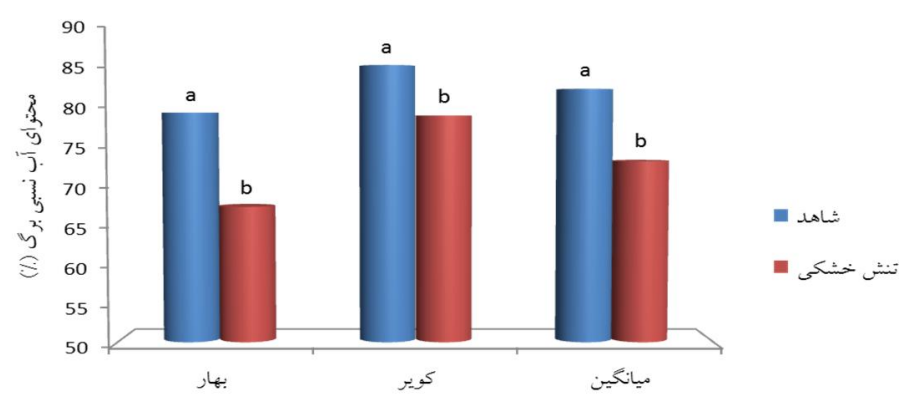

شكل1 - مقايسه ميانكين تركيب تيمارى ارقام كوير و بهار با دو سطح شاهد و تنش خشكى براى صفت محتواى آب نسبى برى

Figure 1. Comparison of mean treatment composition of Kavir and Bahar cultivars with two levels of control and drought stress for leaf relative water content

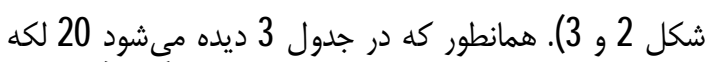

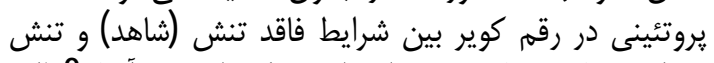

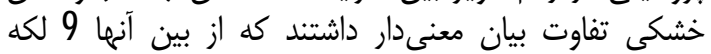

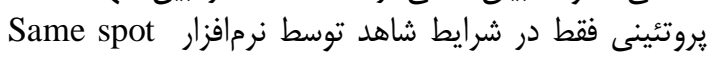
يروتئي

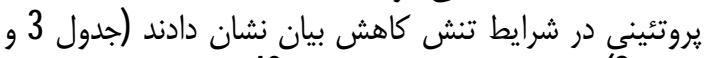
شكل2). علاوه بر اين در رقم بهار 40 لكه بروتئينى كاهش دادي
تحليل الحَوى بروتئينى ارقام كَندم بهاره تحت تنش

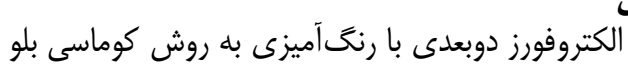

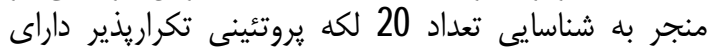

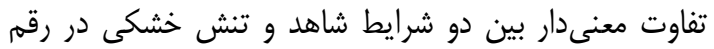

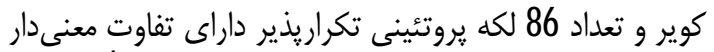

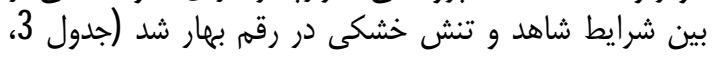




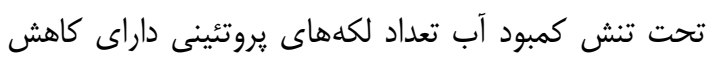

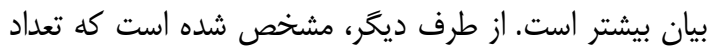

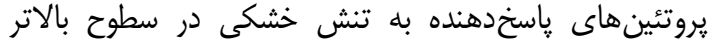

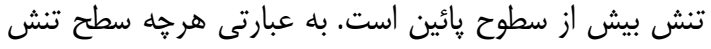

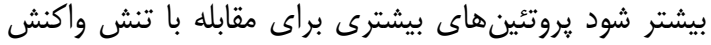

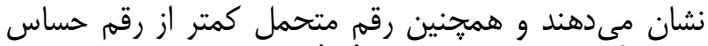

تحت تأثير تنش قرار مى گيرير د (11).
بيان و 46 لكه بروتئينى فقط در شرايط شاهد ديده شدند

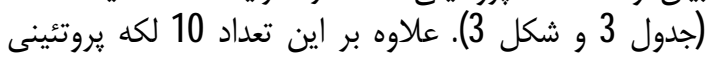
داراى تفاوت معنى دار بين شرايط شاهد و و تنش خشكى اين تعلى بين دو

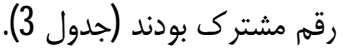
بر اساس مطالعات مختلف مشخص شئر شده است كه در

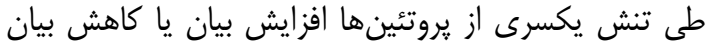

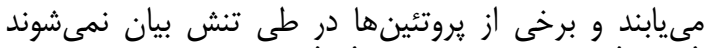
(1133). مشتاق و همكاران (27) عنوان كردند كه در برنج

جدول 三 - لكههاى بروتئينى داراى تغيير بيان معنى دار در دو رقم كوير و بهار و نوع تغيير آنها تحت تنش خشكى Table 3. Protein spots with significant expression change in Kavir and Bahar cultivars and their variation type under

\begin{tabular}{|c|c|c|c|c|c|c|}
\hline \multirow{2}{*}{ 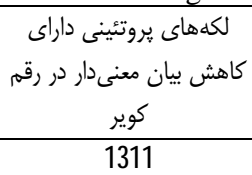 } & \multirow{2}{*}{ 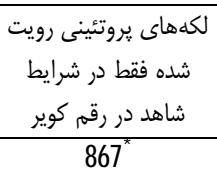 } & \multicolumn{2}{|c|}{ 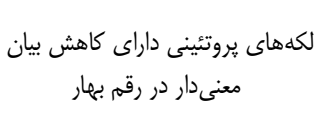 } & \multicolumn{3}{|c|}{ لكههاى بروتئينى رويت شده فقط در شرايط } \\
\hline & & 395 & 562 & $64^{*}$ & $84^{*}$ & 667 \\
\hline $31 C$ & 1295 & 49 & $35]$ & 704 & 911 & 396 \\
\hline $60 A^{*}$ & 992 & 507 & $114 \varepsilon$ & 802 & $70 E$ & 116 \\
\hline $130 E$ & $11 \pi^{*}$ & $71 C$ & 1147 & $5 / \varepsilon$ & $\pi x$ & 116 \\
\hline $8 \mathcal{C}^{*}$ & $5 \pi$ & $8 \pi 5$ & 714 & 55 & $69 E$ & 122 \\
\hline $5 \pi$ & $T 2^{*}$ & 1154 & 1195 & $55 c$ & 491 & 552 \\
\hline $1312^{*}$ & $62_{2}^{*}$ & 354 & 601 & $115 C$ & 920 & \\
\hline $402^{*}$ & $60 E$ & 498 & $8 / 2$ & 581 & 1274 & \\
\hline 1227 & $62^{*}$ & $98 c$ & 110 & 745 & $6 / 2$ & \\
\hline $1151^{*}$ & & ๔ & 115 & $642^{*}$ & 1232 & \\
\hline 1334 & & 716 & $402^{*}$ & 825 & $92 \varepsilon$ & \\
\hline & & 868 & 1150 & 579 & $72^{*}$ & \\
\hline & & 396 & 1226 & 852 & 63 & \\
\hline & & 867 & 465 & 1152 & 835 & \\
\hline & & 549 & 784 & 1169 & 65 & \\
\hline & & $\mathfrak{2 3}$ & 65 & 587 & 1179 & \\
\hline & & 965 & 547 & 61 & 607 & \\
\hline & & 397 & 22 & $1313^{*}$ & 495 & \\
\hline & & 466 & 1272 & 681 & $1151^{*}$ & \\
\hline & & 593 & 1186 & $1173^{*}$ & 1278 & \\
\hline
\end{tabular}



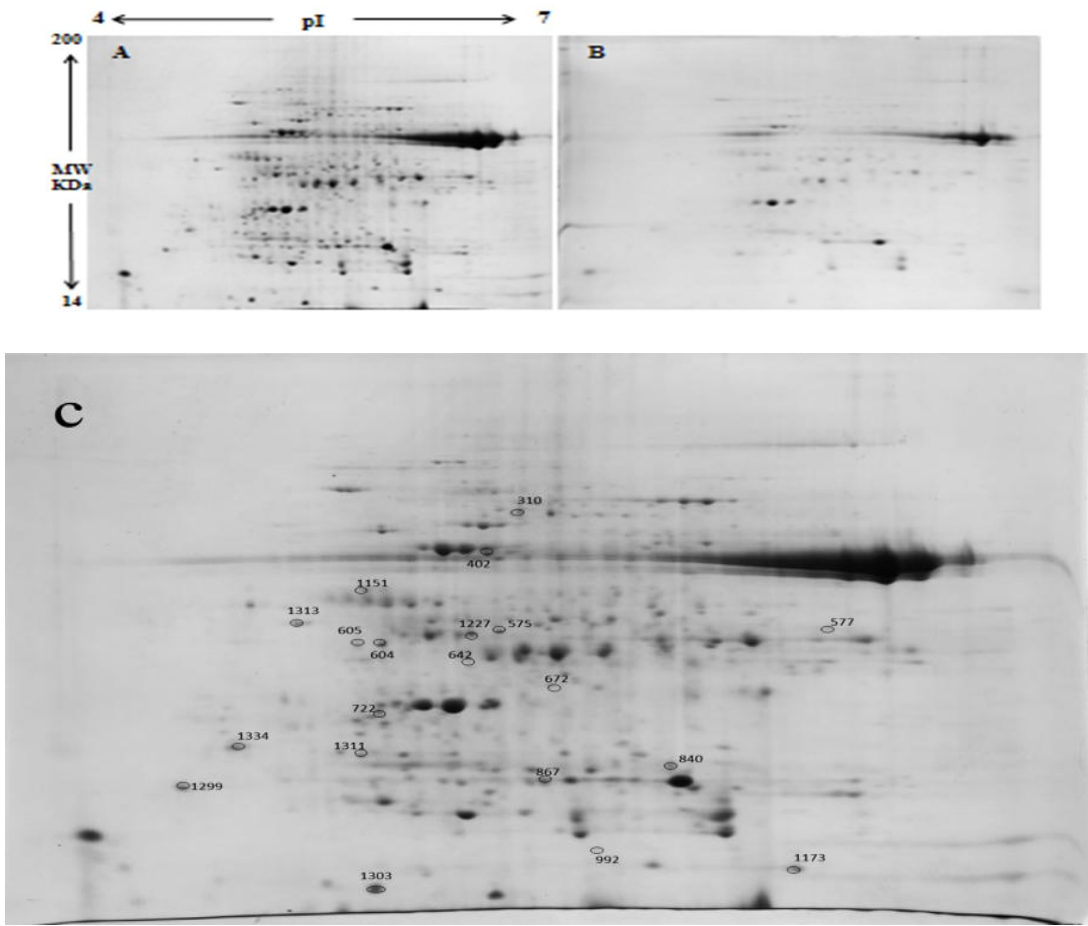

شكل 2- - مقايسه الكوى الكتروفورز دوبعدى رقم كوير در شرايط شاهد (A) با تنش خشكى (B) و لكههاى بروتئينى داراى تغيير

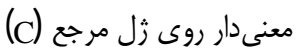

Figure 2. Comparison of two-dimensional electrophoresis pattern of Kavir cultivar in control condition (A) with drought stress (B) and protein spots with significant change on reference gel (C).
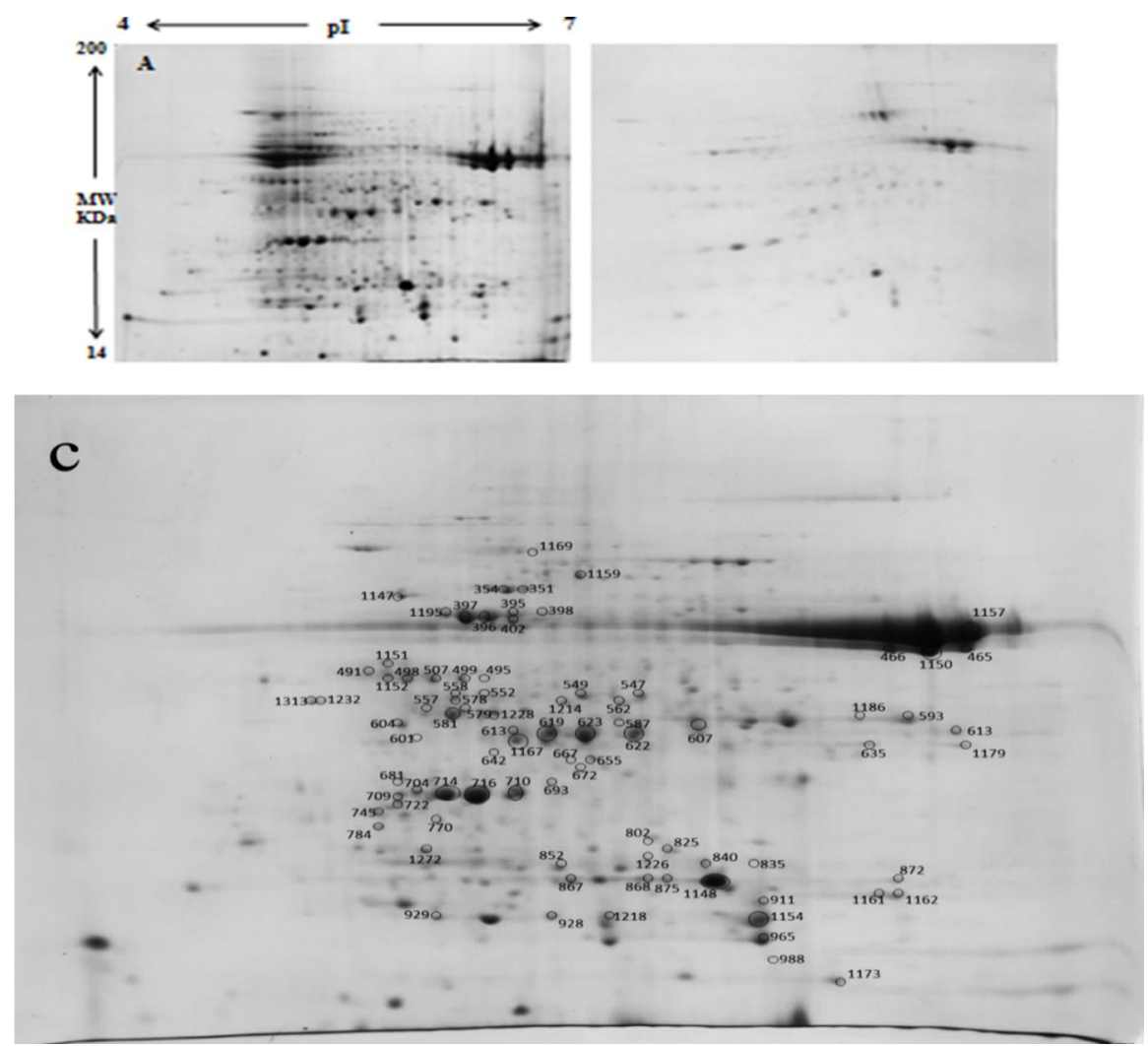

شكل 三 - مقايسه الكوى الكتروفورز دوبعدى رقم بهار در شرايط شاهد (A) با تنش خشكى (B) و لكههاى بروتئينى داراى تغيير معنىدار روى زل (C) (C) مرجع

Figure 2. Comparison of two-dimensional electrophoresis pattern of Bahar cultivar in control condition (A) with drought stress (B) and protein spots with significant change on reference gel (C). 
اين رقم نيز مانند رقم كوير بيشترين درصد يروتئينها مربوط

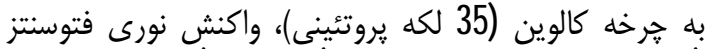

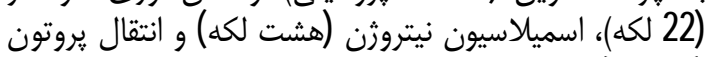

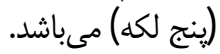

در مجموع كليه بروتئينهاى داراى تغيير بيان معنى داردار

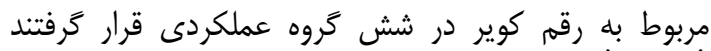

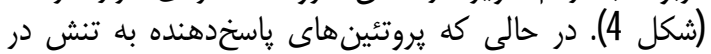

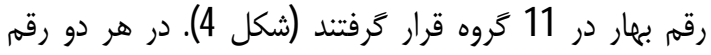

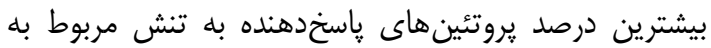

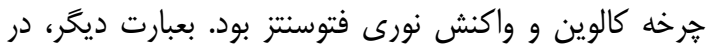

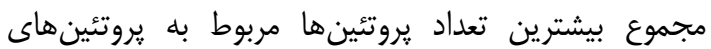

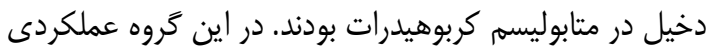

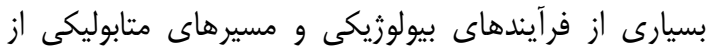

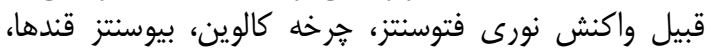

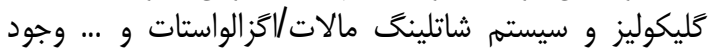

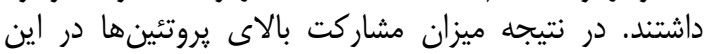

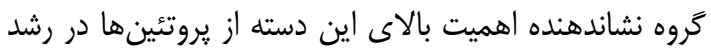

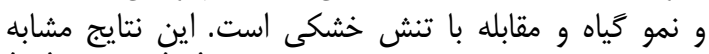
نتايج بدست آمده در مطالعه بروتئوم ذرت (25) و برنج (24) مىباشد.

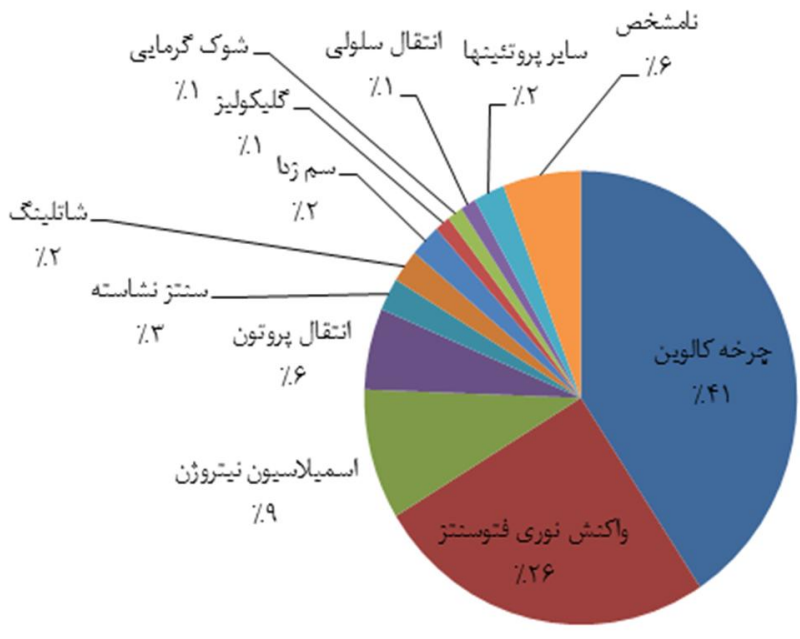

نتايج نشان داد كه در رقمم كوير تعداد 20 لكه يروتئينى

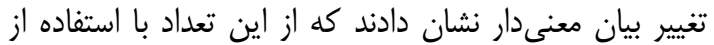

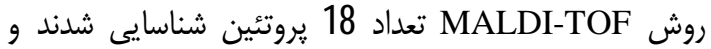
مشخصات اين بروتئينها در جدول 4 آورده شده است. سيس شيس

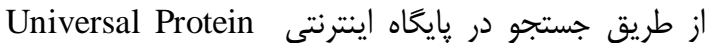
و (http://www.uniprot.org) Sequence database تحقيقات انجام شده در اين زمينه يروتئين هاى داراى تغييرات

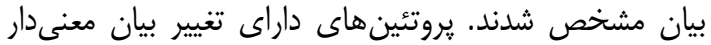

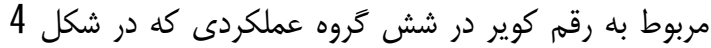

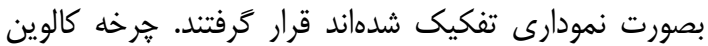

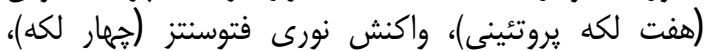

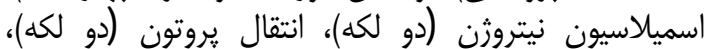

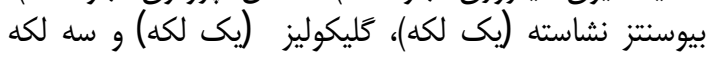

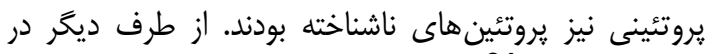

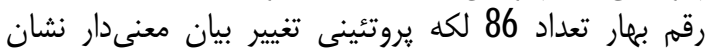

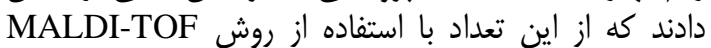

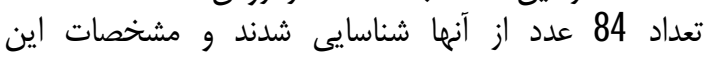

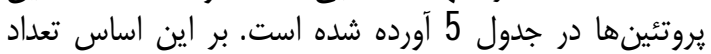

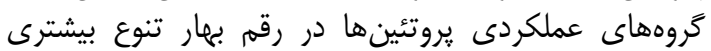

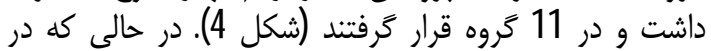

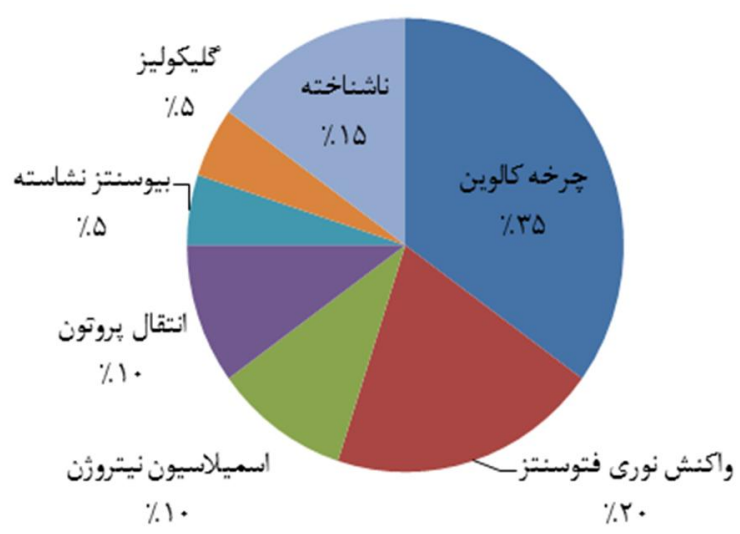

شكل4 - فراوانى نسبى كروههاى عملكردى بروتئينهاى ياسخدهنده به تنش خشكى در رقم كوير (سمت راست) و رقم بهار (سمت جپٍ)

Figure 4. Relative frequency of responsive protein groups to drought stress in Kavir (right) and Bahar (left)

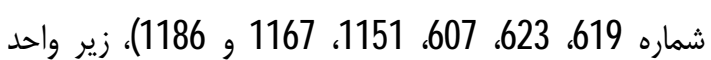

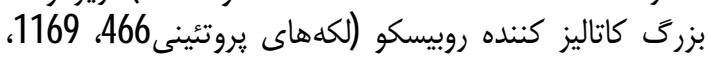

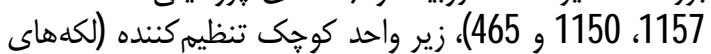

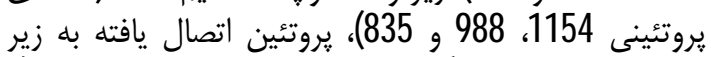

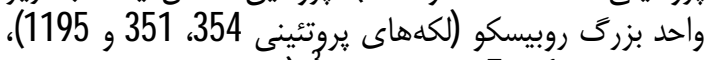

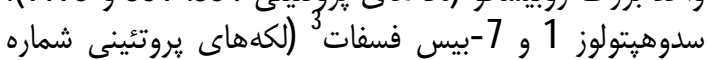

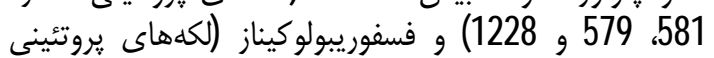

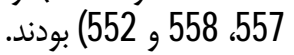

در رقمم كوير بيشترين آنبروتئينها دركَروه خرخه كالوين،

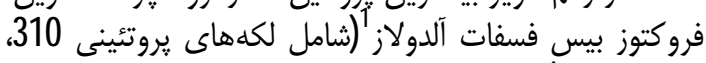
(1751 و 571

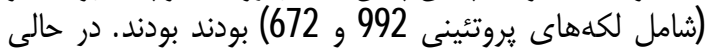

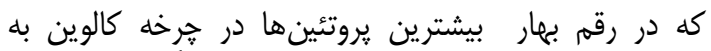

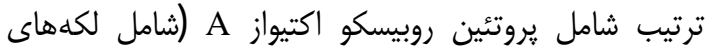

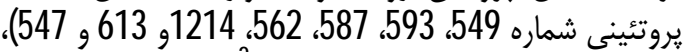
فروكتوز 1 و 6-بيس فسفات آلدولاز2 (لكههاى يروتئينى 
قرار داشتند در مجموع در رقم بهار بيشترين يروتئينها

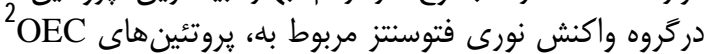

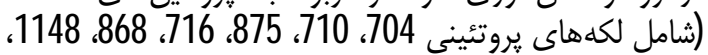
1714، 709، 812، 1162، 929 و 1161) و همجنين بروتئين

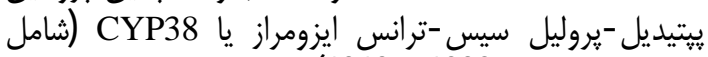

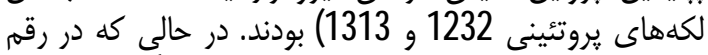

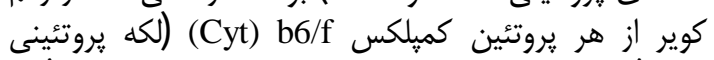

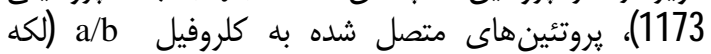

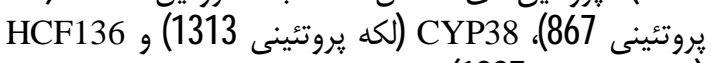

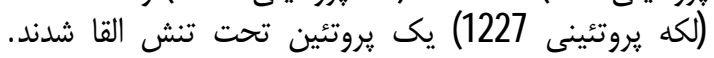

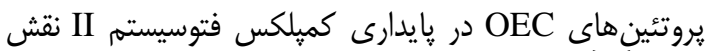

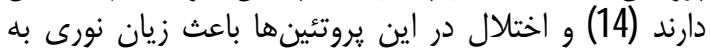

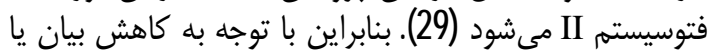

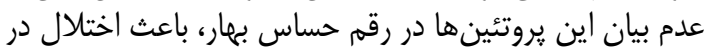

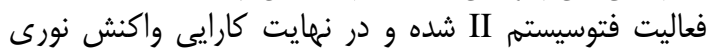

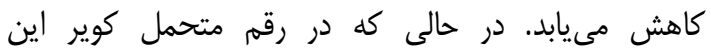

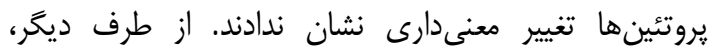

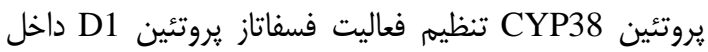

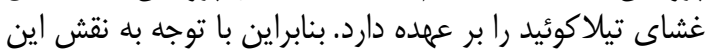

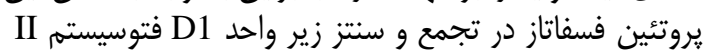
مىتوان اذعان داشت كه بروتئين فئنس

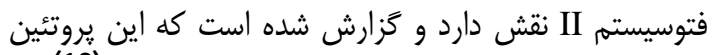

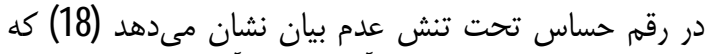

اين نتايج مشابه نتايج بدست آمده از اين آزمايش مئ مى دياشد.

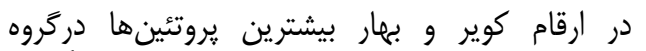

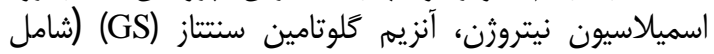

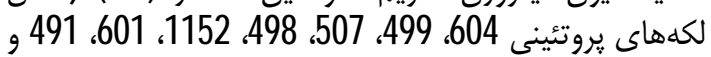

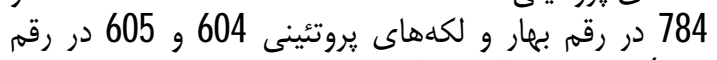
كوير) بود. اين آنزيم، آنزيم كليدى دئى مسير اصلى سلى ساخت

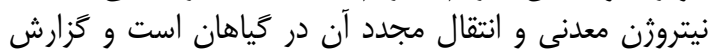

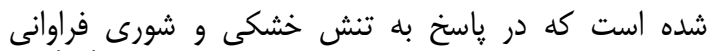

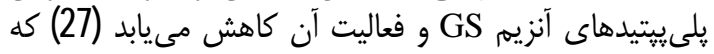

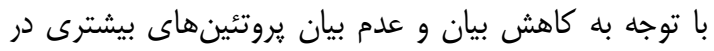

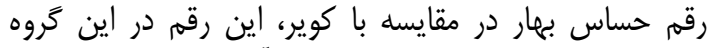

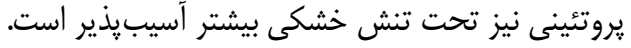

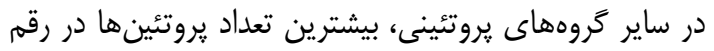

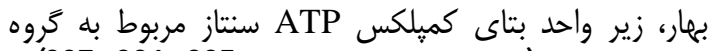

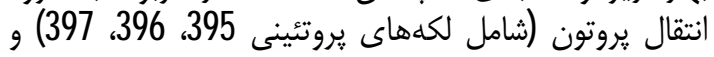

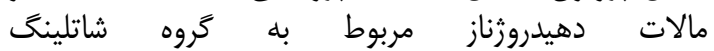

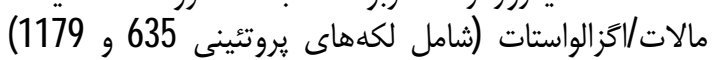

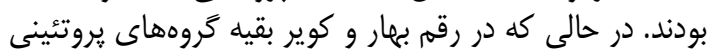

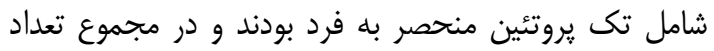

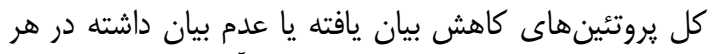

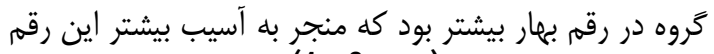
تحت تنش خشكى شد (جدول3 و4).
روبيسكو يك آنزيم كليدى براى تثبيت دى اكسيدكربن

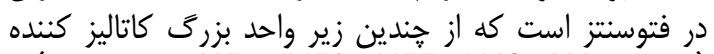

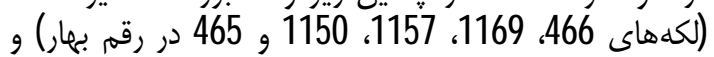

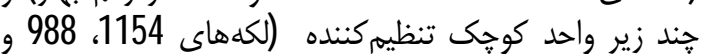

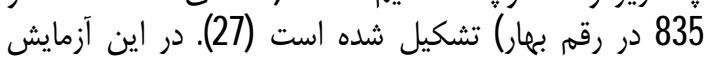

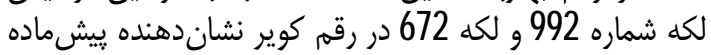

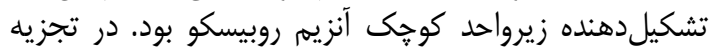

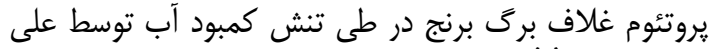

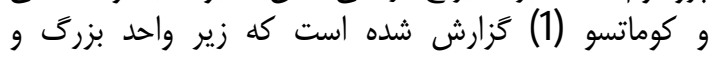

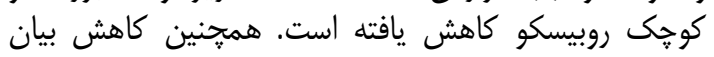

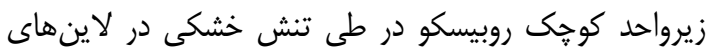

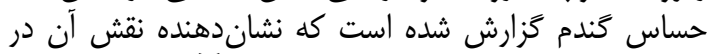

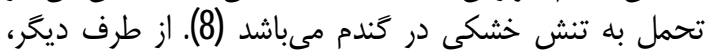

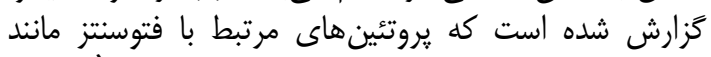

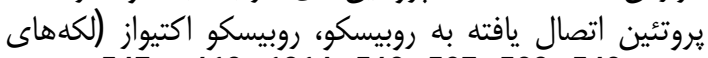

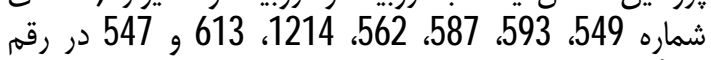

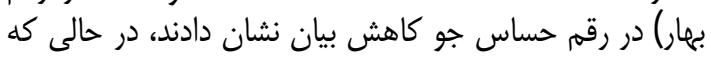

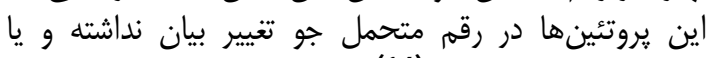
افزايش بيان نشان دادند (16).

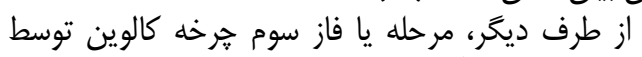

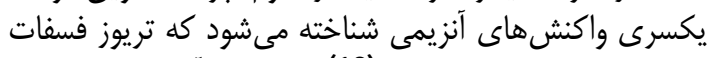

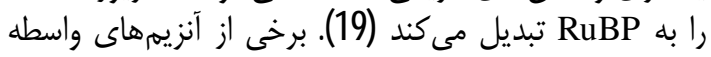

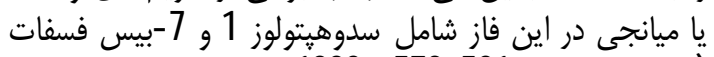

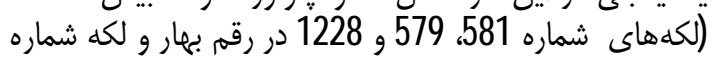

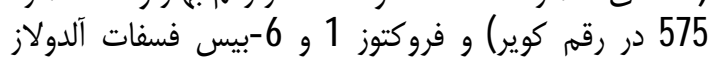

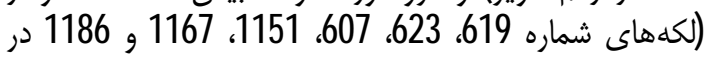

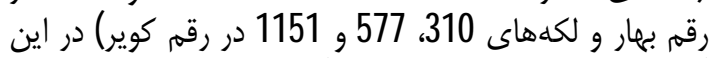

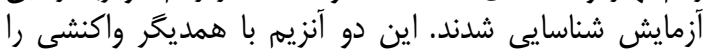

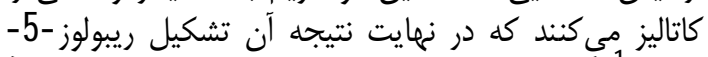

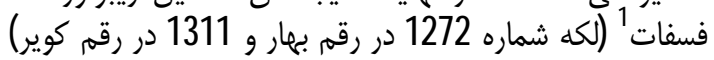

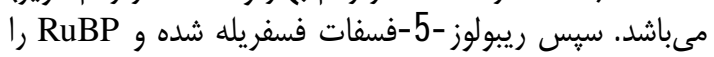

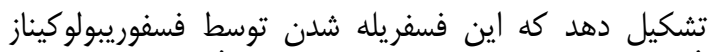

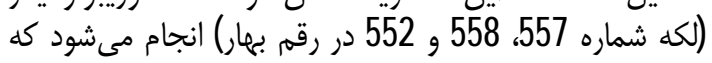

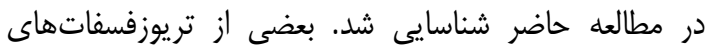

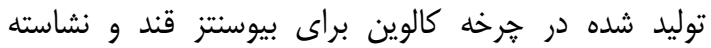

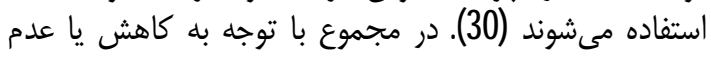

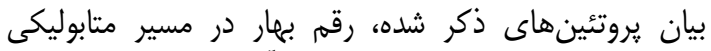
جرخه كالوين تحت تنش خشكى آسيب بيشترى مئين ديبند

(18)

از طرف ديخر تعداد Z 2 يروتئين از رقم بهار در كروه

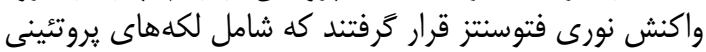

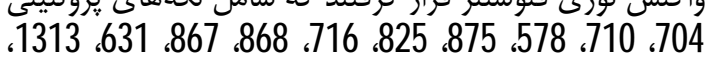
1148، 714، 1173، 709، 872، 112

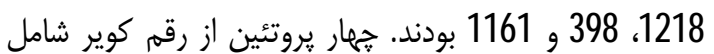
لكههاى شماره 867، 1173، 1313 , 1227 نيز در اين كروه 
جدول4 - اسامى و خصوصيات بروتئينهاى ياسخدهنده به تنش خشكى در رقم كوير

Table 4. Names and characteristics of responsive proteins to drought stress in Kavir

\begin{tabular}{|c|c|c|c|c|c|c|c|c|c|}
\hline 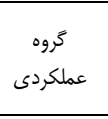 & 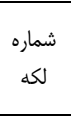 & $\begin{array}{c}\text { Accession } \\
\text { number }\end{array}$ & ن ام يروتئين & score & $\begin{array}{l}\text { Theoretical } \\
\text { MW (KDa) }\end{array}$ & $\begin{array}{l}\text { Theore } \\
\text { tical pI }\end{array}$ & $\begin{array}{c}\text { Experi } \\
\text { mental } \\
\text { MW } \\
\text { (KDa) }\end{array}$ & $\begin{array}{l}\text { Experi } \\
\text { mental } \\
\text { pI }\end{array}$ & Taxonomy \\
\hline \multirow[t]{7}{*}{ كالوين } & 1311 & $\begin{array}{c}\text { gi } \mid 4739542 \\
56\end{array}$ & putative ribose-5-phosphate isomerase & $3 / 5$ & $22 / 50$ & $4 \sqrt{5}$ & $34 / 58$ & $5 / 18$ & $\begin{array}{c}\text { Triticum } \\
\text { urartu }\end{array}$ \\
\hline & 310 & $\begin{array}{c}\text { gi } \mid 4738483 \\
56\end{array}$ & $\begin{array}{l}\text { Fructose-bisphosphate aldolase, } \\
\text { chloroplastic }\end{array}$ & 1012 & $42 / 2$ & $5 / 94$ & $79 / 73$ & $5 / 71$ & $\begin{array}{c}\text { Triticum } \\
\text { urartu }\end{array}$ \\
\hline & 992 & gi $\mid 82619$ & $\begin{array}{l}\text { ribulose-bisphosphate carboxylase (EC } \\
\text { 4.1.1.39) small chain precursor (clone } \\
\text { 234) - wheat (fragment) }\end{array}$ & 130 & $15 / 57$ & $8 / 95$ & $19 / 6$ & $5 / 96$ & $\begin{array}{l}\text { Triticum } \\
\text { aestivum }\end{array}$ \\
\hline & 577 & $\begin{array}{c}\text { gi } \mid 4755521 \\
56\end{array}$ & $\begin{array}{c}\text { Fructose-bisphosphate aldolase, } \\
\text { cytoplasmic isozyme } 1\end{array}$ & 932 & $37 / 23$ & $6 / 38$ & $57 / 31$ & 673 & $\begin{array}{c}\text { Aegilops } \\
\text { tauschii }\end{array}$ \\
\hline & $5 / 5$ & gi||1173347 & $\begin{array}{c}\text { Full=Sedoheptulose-1,7-bisphosphatase, } \\
\text { chloroplastic }\end{array}$ & 389 & $42 / 55$ & 604 & $57 / 41$ & $5 / 64$ & $\begin{array}{l}\text { Triticum } \\
\text { aestivum }\end{array}$ \\
\hline & 1151 & gi|119745 & $\begin{array}{l}\text { Full=Fructose-1,6-bisphosphatase, } \\
\text { chloroplastic }\end{array}$ & 261 & $44 / 70$ & $5 / 16$ & $64 / 88$ & $5 / 20$ & $\begin{array}{l}\text { Triticum } \\
\text { aestivum }\end{array}$ \\
\hline & $6 / 2$ & gi $\mid 82619$ & $\begin{array}{l}\text { ribulose-bisphosphate carboxylase (EC } \\
\text { 4.1.1.39) small chain precursor (clone } \\
\text { 234) - wheat (fragment) }\end{array}$ & 68 & $15 / 57$ & $8 / 95$ & $47 / 51$ & $5 / 80$ & $\begin{array}{l}\text { Triticum } \\
\text { aestivum }\end{array}$ \\
\hline \multirow[t]{4}{*}{ 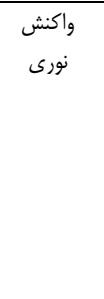 } & 867 & $\begin{array}{c}\text { gi } \mid 4741216 \\
85\end{array}$ & $\begin{array}{l}\text { Chlorophyll a-b binding protein } 8 \\
\text { chloroplastic }\end{array}$ & 510 & $29 / 30$ & $8 / 69$ & $30 / 24$ & $5 / 78$ & $\begin{array}{c}\text { Triticum } \\
\text { urartu }\end{array}$ \\
\hline & 1173 & $\begin{array}{c}\text { gi } \mid 6856619 \\
1\end{array}$ & $\begin{array}{l}\text { Cytochrome b6-f complex iron-sulfur } \\
\text { subunit, chloroplastic }\end{array}$ & 357 & $24 / 11$ & $8 / 47$ & $16 / 78$ & 6ळ3 & $\begin{array}{l}\text { Triticum } \\
\text { aestivum }\end{array}$ \\
\hline & 1313 & $\begin{array}{c}\text { gi } \mid 4742193 \\
38\end{array}$ & $\begin{array}{l}\text { Peptidyl-prolyl cis-trans isomerase } \\
\text { CYP38, chloroplastic }\end{array}$ & 741 & $46 / 10$ & $4 / 82$ & $58 / 6$ & $4 / 97$ & $\begin{array}{c}\text { Triticum } \\
\text { urartu }\end{array}$ \\
\hline & 1227 & $\begin{array}{c}\text { gi } \mid 3571170 \\
71\end{array}$ & $\begin{array}{l}\text { photosystem II stability/assembly factor } \\
\text { HCF136, chloroplastic-like }\end{array}$ & 812 & $37 / 01$ & $5 / 40$ & $56 / 91$ & $5 / 55$ & $\begin{array}{l}\text { Brachypodiu } \\
\text { m distachyon }\end{array}$ \\
\hline \multirow[t]{2}{*}{ ن استميلاسيو } & 604 & gi|121340 & $\begin{array}{l}\text { Full=Glutamine synthetase leaf isozyme, } \\
\text { chloroplastic }\end{array}$ & 684 & $47 / 41$ & $5 / 11$ & $55 / 09$ & $5 / 25$ & $\begin{array}{l}\text { Hordeum } \\
\text { vulgare }\end{array}$ \\
\hline & 605 & gi|121340 & $\begin{array}{l}\text { Full=Glutamine synthetase leaf isozyme, } \\
\text { chloroplastic }\end{array}$ & 450 & $47 / 41$ & $5 / 11$ & $54 / 99$ & $5 / 17$ & $\begin{array}{c}\text { Hordeum } \\
\text { vulgare }\end{array}$ \\
\hline \multirow[t]{2}{*}{ 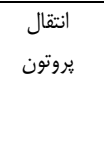 } & 1299 & $\begin{array}{c}\text { gi } \mid 4756277 \\
17\end{array}$ & ATP synthase delta chain, chloroplastic & 361 & $17 / 72$ & $4 / 49$ & $28 / 73$ & $4 / 59$ & $\begin{array}{c}\text { Aegilops } \\
\text { tauschii }\end{array}$ \\
\hline & 402 & gi|525291 & ATP synthase beta subunit & 1265 & $59 / 33$ & $5 / 56$ & $71 / 6$ & $5 / 60$ & $\begin{array}{l}\text { Triticum } \\
\text { aestivum }\end{array}$ \\
\hline 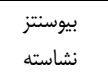 & 722 & $\begin{array}{c}\text { gi } \mid 4737873 \\
83\end{array}$ & $\begin{array}{l}\text { Soluble inorganic pyrophosphatase } 1, \\
\text { chloroplastic }\end{array}$ & 369 & $31 / 70$ & $5 / 00$ & $42 / 77$ & $5 / 24$ & $\begin{array}{c}\text { Triticum } \\
\text { urartu }\end{array}$ \\
\hline 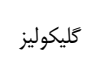 & 840 & gi|1174749 & $\begin{array}{l}\text { Full=Triosephosphate isomerase, } \\
\text { cytosolic }\end{array}$ & 149 & $27 / 14$ & $5 / 24$ & $32 / 6$ & $6 / 21$ & $\begin{array}{l}\text { Secale } \\
\text { cereale }\end{array}$ \\
\hline \multirow[t]{3}{*}{ 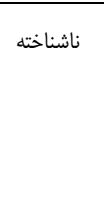 } & 1303 & - & & & & & $15 / 13$ & $5 / 63$ & \\
\hline & 1334 & $\begin{array}{c}\text { gi } \mid 2265338 \\
70\end{array}$ & cp31BHv [Triticum aestivum] & 314 & $18 / 99$ & $4 / 85$ & $36 / 00$ & $4 / 76$ & $\begin{array}{l}\text { Triticum } \\
\text { aestivum }\end{array}$ \\
\hline & 642 & - & & & & & $51 / 05$ & $5 / 54$ & \\
\hline
\end{tabular}


جدول 5 - اسامى و خصوصيات بروتئين هاى باسخدهنده به تنش خشكى در رقم بعهار Table 5. Names and characteristics of responsive proteins to drought stress in Bahar

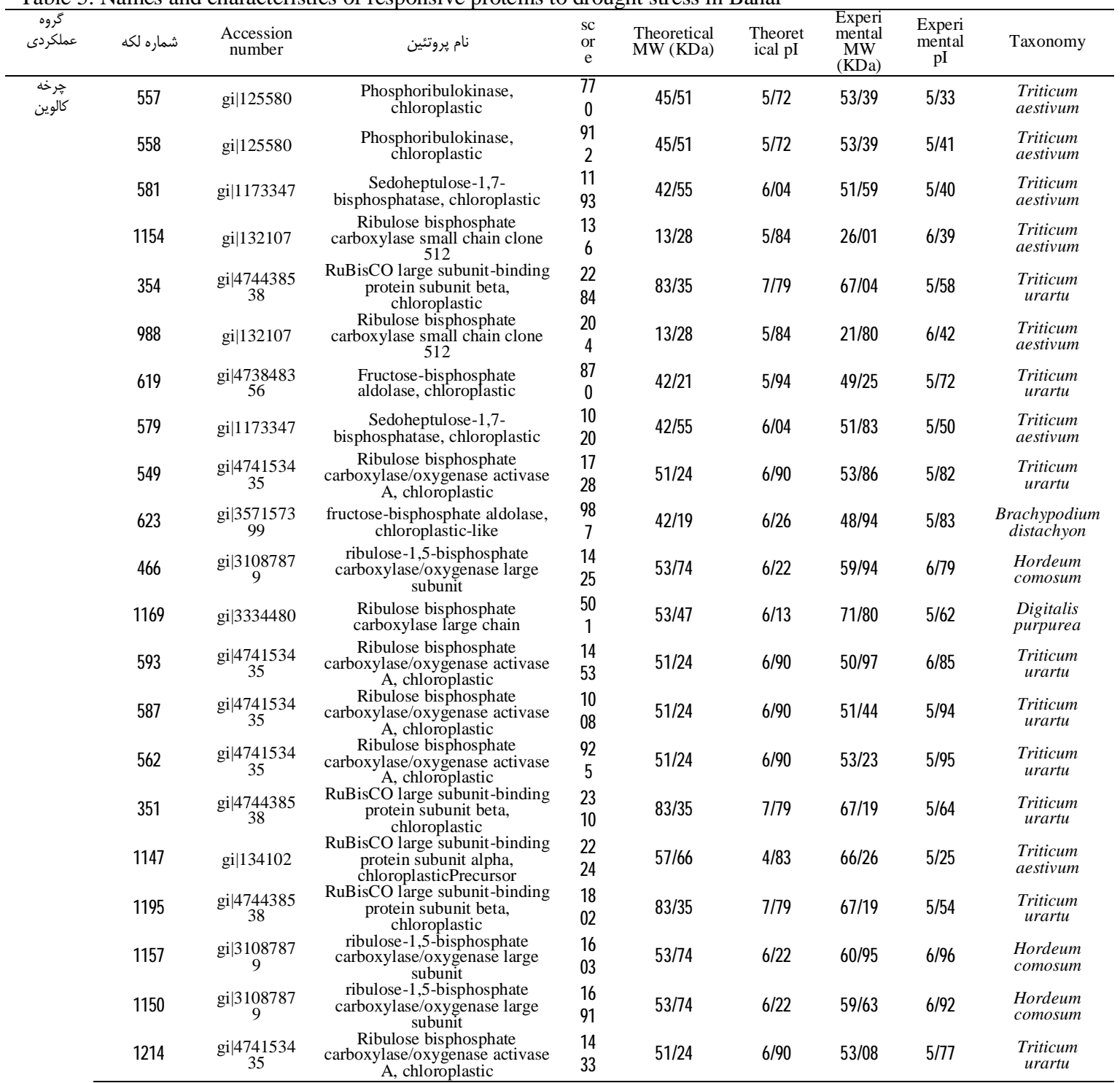




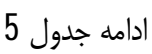

Continued Table 5

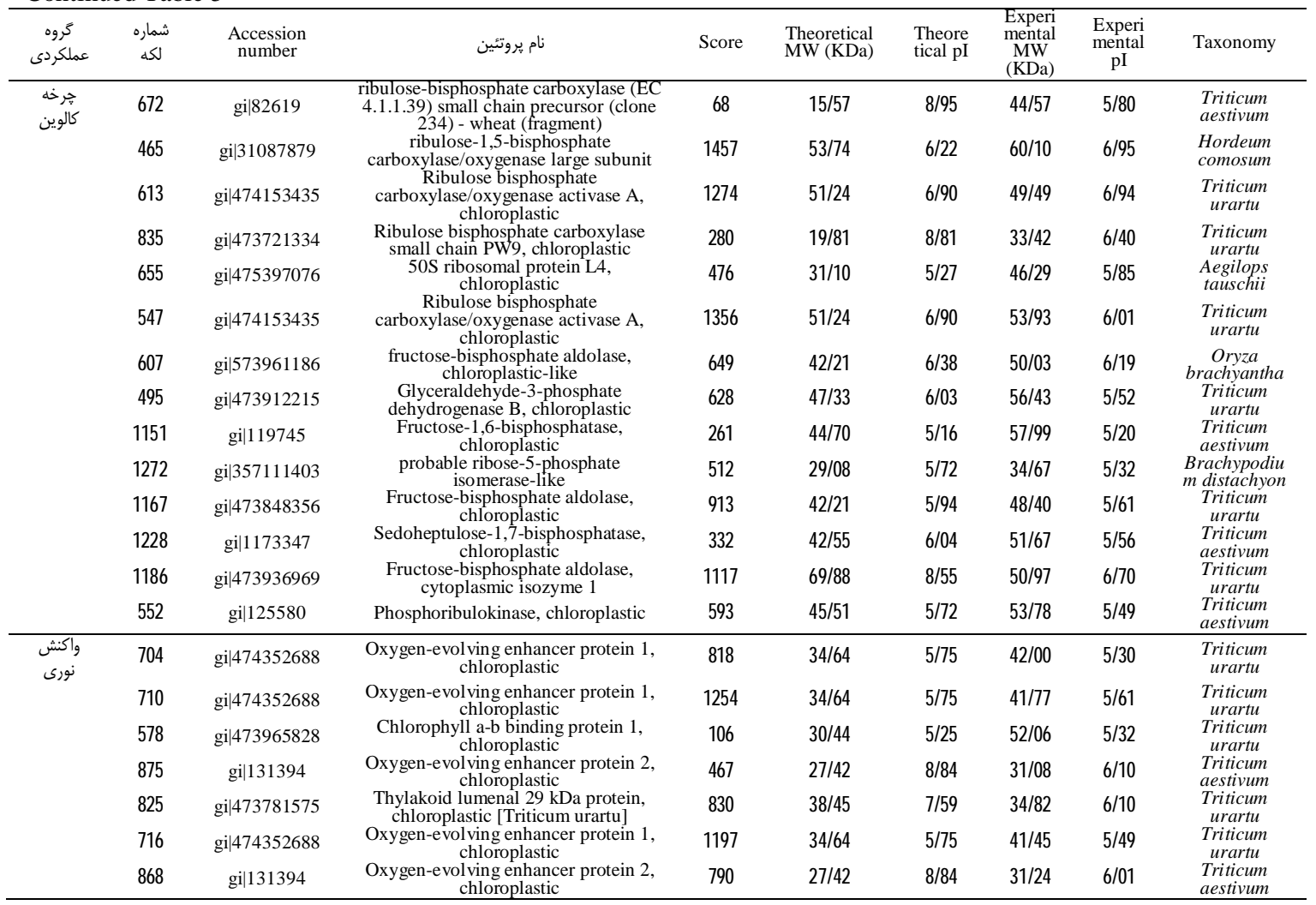


Continued Table 5

ادامه جدول

\begin{tabular}{|c|c|c|c|c|c|c|c|c|c|}
\hline 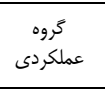 & ل الكه - اره & $\begin{array}{l}\text { Accession } \\
\text { number }\end{array}$ & 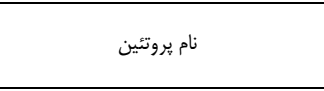 & score & $\begin{array}{l}\text { Theoretical } \\
\text { MW (KDa) }\end{array}$ & $\begin{array}{c}\text { Theoretica } \\
1 \mathrm{pI}\end{array}$ & $\begin{array}{l}\text { Experim } \\
\text { ental } \\
\text { MW } \\
\text { (KDa) } \\
\end{array}$ & $\begin{array}{c}\text { Experimental } \\
\mathrm{pI}\end{array}$ & Taxonomy \\
\hline \multirow[t]{15}{*}{ واكنش نورى } & 867 & gi|474121685 & $\begin{array}{l}\text { Chlorophyll a-b binding protein } \\
\text { 8, chloroplastic }\end{array}$ & 510 & $29 / 30$ & $8 / 69$ & $31 / 24$ & $5 / 78$ & Triticum urartu \\
\hline & 61 & gi|357117071 & $\begin{array}{l}\text { photosystem II stability/assembly } \\
\text { factor HCF136, chloroplastic-like }\end{array}$ & $8 / 2$ & 37/01 & $5 / 40$ & $48 / 32$ & $5 / 54$ & Brachypodium distachyon \\
\hline & 1313 & gi|474219338 & $\begin{array}{l}\text { Peptidyl-prolyl cis-trans } \\
\text { isomerase CYP38, chloroplastic }\end{array}$ & 741 & $46 / 10$ & $4 / 82$ & $53 / 15$ & $4 / 97$ & Triticum urartu \\
\hline & 1148 & gi|131394 & $\begin{array}{l}\text { Oxygen-evolving enhancer } \\
\text { protein 2, chloroplastic }\end{array}$ & 886 & $27 / 42$ & $8 / 84$ & 3061 & $6 / 24$ & Triticum aestivum \\
\hline & 714 & gi|474352688 & $\begin{array}{l}\text { Oxygen-evolving enhancer } \\
\text { protein 1, chloroplastic }\end{array}$ & 1068 & $34 / 64$ & $5 / 75$ & $41 / 53$ & $5 / 39$ & Triticum urartu \\
\hline & 1173 & gi|68566191 & $\begin{array}{l}\text { Cytochrome b6-f complex iron- } \\
\text { sulfur subunit, chloroplastic }\end{array}$ & 357 & 24/11 & $8 / 47$ & $18 / 52$ & 663 & Triticum aestivum \\
\hline & 709 & gi|474352688 & $\begin{array}{l}\text { Oxygen-evolving enhancer } \\
\text { protein 1, chloroplastic }\end{array}$ & 899 & $34 / 64$ & $5 / 75$ & $41 / 77$ & $5 / 25$ & Triticum urartu \\
\hline & $8 / 2$ & gi|131394 & $\begin{array}{l}\text { Oxygen-evolving enhancer } \\
\text { protein } 2 \text {, chloroplastic }\end{array}$ & 462 & $27 / 42$ & $8 / 84$ & $31 / 16$ & 682 & Triticum aestivum \\
\hline & 1162 & gi|131394 & $\begin{array}{l}\text { Oxygen-evolving enhancer } \\
\text { protein 2, chloroplastic }\end{array}$ & 688 & $27 / 42$ & $8 / 84$ & $29 / 05$ & 682 & Triticum aestivum \\
\hline & 929 & gi|131394 & $\begin{array}{l}\text { Oxygen-evolving enhancer } \\
\text { protein 2, chloroplastic }\end{array}$ & 280 & $27 / 42$ & $8 / 84$ & $26 / 48$ & $5 / 36$ & Triticum aestivum \\
\hline & 1232 & gi|474219338 & $\begin{array}{l}\text { Peptidyl-prolyl cis-trans } \\
\text { isomerase CYP38, chloroplastic }\end{array}$ & 602 & $46 / 10$ & $4 / 82$ & $53 / 39$ & $5 / 01$ & Triticum urartu \\
\hline & 928 & gi|544700 & $\begin{array}{l}\text { light-harvesting complex I, } \\
\text { partial (chloroplast) }\end{array}$ & 325 & $24 / 44$ & $8 / 11$ & $26 / 56$ & $5 / 73$ & Hordeum vulgare \\
\hline & 1218 & gi $\mid 18650668$ & $\begin{array}{l}\text { temperature stress-induced } \\
\text { lipocalin }\end{array}$ & 491 & 21/81 & $5 / 50$ & 26/01 & $5 / 90$ & Triticum aestivum \\
\hline & 398 & gi|474105633 & $\begin{array}{l}\text { ATP-dependent zinc } \\
\text { metalloprotease FTSH 2, } \\
\text { chloroplastic }\end{array}$ & 500 & $71 / 99$ & $5 / 70$ & ॐ/53 & $5 / 67$ & Triticum urartu \\
\hline & 116 & gi|131394 & $\begin{array}{l}\text { Oxygen-evolving enhancer } \\
\text { protein } 2 \text {, chloroplastic }\end{array}$ & ๒0 & $27 / 42$ & $8 / 84$ & 29/13 & 678 & Triticum aestivum \\
\hline \multirow[t]{6}{*}{ اسميلاسيون } & 604 & gi|121340 & $\begin{array}{l}\text { Glutamine synthetase leaf } \\
\text { isozyme, chloroplastic }\end{array}$ & 684 & 47/41 & $5 / 11$ & $50 / 42$ & $5 / 25$ & Hordeum vulgare \\
\hline & 499 & gi|71362640 & $\begin{array}{l}\text { plastid glutamine synthetase } \\
\text { isoform GS2c }\end{array}$ & 1161 & $47 / 02$ & $5 / 75$ & 5612 & $5 / 43$ & Triticum aestivum \\
\hline & 507 & gi|121340 & $\begin{array}{l}\text { Glutamine synthetase leaf } \\
\text { isozyme, chloroplastic }\end{array}$ & 224 & $47 / 41$ & $5 / 11$ & $55 / 96$ & $5 / 34$ & Hordeum vulgare \\
\hline & 498 & gi|121340 & $\begin{array}{l}\text { Glutamine synthetase leaf } \\
\text { isozyme, chloroplastic }\end{array}$ & $3 / 2$ & 47/41 & $5 / 11$ & $56 / 12$ & $5 / 27$ & Hordeum vulgare \\
\hline & 1152 & gi|121340 & $\begin{array}{l}\text { Glutamine synthetase leaf } \\
\text { isozyme, chloroplastic }\end{array}$ & 583 & $47 / 41$ & $5 / 11$ & $56 / 51$ & $5 / 27$ & Hordeum vulgare \\
\hline & 601 & gi|121340 & $\begin{array}{l}\text { Glutamine synthetase leaf } \\
\text { isozyme, chloroplastic }\end{array}$ & 588 & $47 / 41$ & $5 / 11$ & $50 / 50$ & $5 / 34$ & Hordeum vulgare \\
\hline
\end{tabular}


Continued Table 5.

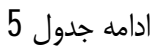

\begin{tabular}{|c|c|c|c|c|c|c|c|c|c|}
\hline عملكردى & 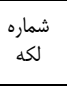 & $\begin{array}{l}\text { Accession } \\
\text { number }\end{array}$ & 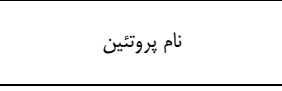 & $\begin{array}{l}\text { Sco } \\
\text { re }\end{array}$ & $\begin{array}{l}\text { Theoretical } \\
\text { MW (KDa) }\end{array}$ & $\begin{array}{l}\text { Theoreti } \\
\text { cal pI }\end{array}$ & $\begin{array}{l}\text { Experim } \\
\text { ental } \\
\text { MW } \\
\text { (KDa) } \\
\end{array}$ & $\begin{array}{l}\text { Experim } \\
\text { ental pI }\end{array}$ & Taxonomy \\
\hline \multirow[t]{2}{*}{ اسميلاسيون } & 491 & gi|71362640 & $\begin{array}{l}\text { plastid glutamine synthetase } \\
\text { isoform GS2c }\end{array}$ & 670 & 47/102 & $5 \sqrt{15}$ & 5682 & $5 / 14$ & $\begin{array}{l}\text { Triticum } \\
\text { aestivum }\end{array}$ \\
\hline & 784 & gi|71361900 & $\begin{array}{l}\text { glutamine synthetase isoform } \\
\text { GS1a }\end{array}$ & 156 & $39 / 40$ & $5 / 41$ & $37 / 7$ & $5 / 18$ & $\begin{array}{l}\text { Triticum } \\
\text { aestivum }\end{array}$ \\
\hline \multirow[t]{4}{*}{ انتقال يروتون } & 395 & gi|14017579 & $\underset{\text { subunit }}{\text { ATP synthase CF1 beta }}$ & $\begin{array}{c}166 \\
5\end{array}$ & $53 / 88$ & $5 / 06$ & 3/92 & $5 / 59$ & $\begin{array}{l}\text { Triticum } \\
\text { aestivum }\end{array}$ \\
\hline & 397 & gi|14017579 & $\begin{array}{c}\text { ATP synthase CF1 beta } \\
\text { subunit }\end{array}$ & $\begin{array}{c}181 \\
\epsilon\end{array}$ & $53 / 88$ & $5 / 06$ & ஒ/ & $5 / 45$ & $\begin{array}{l}\text { Triticum } \\
\text { aestivum }\end{array}$ \\
\hline & 402 & gi|525291 & ATP synthase beta subunit & $\frac{126}{5}$ & $59 / 33$ & $5 / 56$ & अ/22 & $5 / 60$ & $\begin{array}{l}\text { Triticum } \\
\text { aestivum }\end{array}$ \\
\hline & 1226 & gi|47607439 & $\begin{array}{l}\text { mitochondrial ATP synthase } \\
\text { precursor }\end{array}$ & 829 & $27 / 09$ & $7 / 7$ & $33 / 34$ & $6 / 03$ & $\begin{array}{l}\text { Triticum } \\
\text { aestivum }\end{array}$ \\
\hline \multirow[t]{2}{*}{ شاتلينگ ستم } & 65 & gi|475577109 & $\begin{array}{l}\text { Malate dehydrogenase } 1, \\
\text { mitochondrial }\end{array}$ & ๓3 & $34 / 93$ & $5 / 26$ & $48 / 08$ & 672 & $\begin{array}{c}\text { Aegilops } \\
\text { tauschii }\end{array}$ \\
\hline & 1179 & gi|475577109 & $\begin{array}{c}\text { Malate dehydrogenase } 1, \\
\text { mitochondrial }\end{array}$ & 639 & $34 / 93$ & $5 / 26$ & $47 / 85$ & $6 / 95$ & $\begin{array}{c}\text { Aegilops } \\
\text { tauschii }\end{array}$ \\
\hline \multirow[t]{2}{*}{ سمزدا } & 911 & gi|474023258 & $\begin{array}{c}\text { Glutathione S-transferase } \\
\text { DHAR2 }\end{array}$ & 593 & $45 / 26$ & $8 / 30$ & 28/12 & $6 / 38$ & $\begin{array}{l}\text { Triticum } \\
\text { urartu }\end{array}$ \\
\hline & 667 & gi|7619802 & putative glyoxalase I & 463 & $31 / 83$ & $5 / 39$ & $45 / 28$ & $5 / 74$ & $\begin{array}{l}\text { Triticum } \\
\text { aestivum }\end{array}$ \\
\hline كليكوليز & 840 & gi|1174749 & $\begin{array}{c}\text { Triosephosphate isomerase, } \\
\text { cytosolic }\end{array}$ & 149 & $27 / 14$ & $5 / 24$ & 33/11 & $6 / 27$ & Secale cereale \\
\hline شوى گرمايى & 1159 & gi|473970552 & $\begin{array}{c}\text { Heat shock } 70 \text { kDa protein, } \\
\text { mitochondrial }\end{array}$ & 745 & $76 / 36$ & $6 / 16$ & 7063 & $5 / 83$ & $\begin{array}{c}\text { Triticum } \\
\text { urartu }\end{array}$ \\
\hline 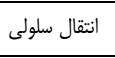 & 61 & gi|475620929 & $\begin{array}{c}\text { Alpha-soluble NSF } \\
\text { attachment protein }\end{array}$ & 776 & $35 / 16$ & 4/96 & $43 / 40$ & $5 / 25$ & $\begin{array}{l}\text { Aegilops } \\
\text { tauschii }\end{array}$ \\
\hline \multirow{2}{*}{ 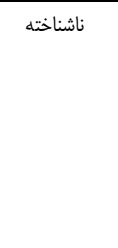 } & 770 & gi|38679331 & harpin binding protein 1 & 697 & $29 / 52$ & 9/51 & 38/6 & $5 / 37$ & $\begin{array}{l}\text { Triticum } \\
\text { aestivum }\end{array}$ \\
\hline & 22 & - & & & & & $49 / 18$ & $5 / 99$ & \\
\hline
\end{tabular}

يروتئينها دركروه خرخه كالوين بترتيب در رقم كوير و بهار

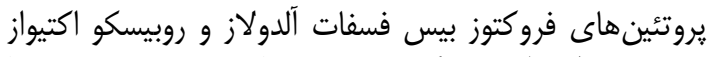

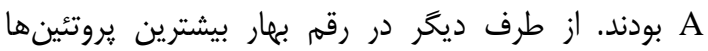

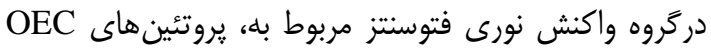

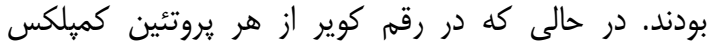

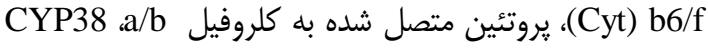

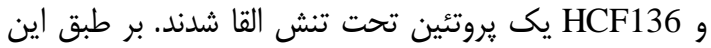

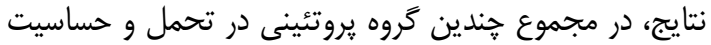

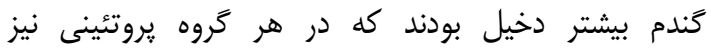
يروتئينهاى خاصى در مكانيسم تحمل و حساسيت بردي بيشتر

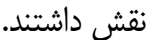

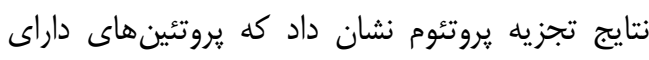

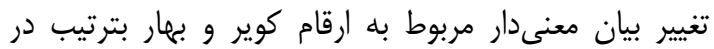

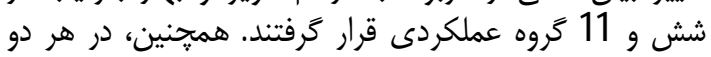

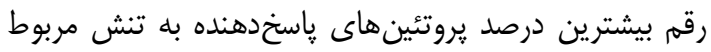

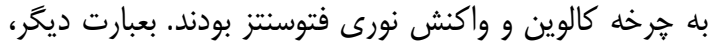

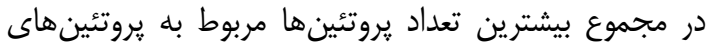

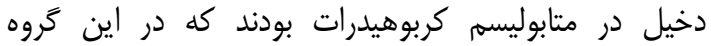

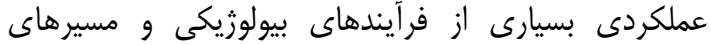

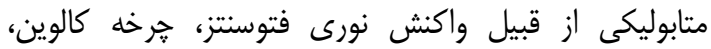

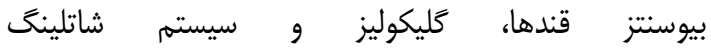
مالات/اءزالواستات وجود داشتند. بطور كلى، بيشترين 
1. Ali, G.M. and S. Komatsu. 2006. Proteomic Analysis of Rice Leaf Sheath during Drought Stress. Journal of Proteome Research, 5(2): 396-403.

2. Arias, D. 2007. Calibration of LAI-2000 to Estimate Leaf Area Index and Assessment of its Relationship with stand productivity in six Native and Introduced tree Species in costarica. Forest Ecology and Management, 247: 85-193.

3. Bray, E.A. 2002. Classification of genes differentially expressed during water-deficit stress in Arabidopsis thaliana: An analysis using microarray and differential expression data. Annals of Botany, 89: 803-811.

4. Caruso, G., C. Cavaliere, P. Foglia, R. Gubbiotti, R. Samperi and A. Laganà. 2009. Analysis of drought responsive proteins in wheat (Triticum durum) by 2D-PAGE and MALDI-TOF mass spectrometry. Plant Science, 177: 570-576.

5. Chang, W.W., L. Huang, M. Shen, C. Webster, A.L. Burlingame and J.K. Roberts. 2000. Patterns of protein synthesis and tolerance of anoxia in root tips of maize seedlings acclimated to a low-oxygen environment and identification of proteins by mass spectrometry. Plant Physiology, 122: 295-318.

6. Costa, R., N. Bahrman, J.M. Frigerio, A. Kremer and C. Plomion. 1998. Water deficit-response proteins in maritime pines. Plant Molecular Biology, 38: 587-596.

7. Damerval, C., D. De Vienne, M. Zivy and H. Thiellement. 1986. Technical improvements in twodimensional electrophoresis increase the level of genetic variation detected in wheat-seedling roteins. Electrophoresis, 7: 52-4.

8. Demirevska, K., D. Zasheva, R. Dimitrov, L. Simova-Stoilova, M. Stamenova, and M. Feller. 2009. Drought stress effects on rubisco in wheat: Changes in the rubisco large subunit. Acta Physiologiae Plantarum, 31: 1129-1138.

9. Derogar, H., B. Fakheri, N. Mehdinezhad and R. Mohammadi. 2019. Evaluation of some biochemical traits in cultivars and wild species of wheat under drought stress. Environmental Stresses in Crop Sciences, 12(3): 685-696. (In Persian).

10. Firoozi, B., O. Sofalian, M. Shokrpour, A. Rasoulzadeh and F. Ahmadpoor. 2012. Assessment of Drought Tolerance Indices and their Relation with ISSR Markers in Bread Wheat (Triticum aestivum L.). Notulae Scientia Biologicae, 4(3): 143-150.

11. Hashimoto, M. and S. Komatsu. 2007. Proteomic analysis of rice seedling during cold stress. Proteomics, 7: 293-302.

12. Hurkman, W.J. and C.K. Tanaka. 1987. The effect of salt on the pattern of protein synthesis in barley roots. Plant Physiology, 83: 517-524.

13. Hurkman, W.J., C.K. Tanaka and F.M. Dupont. 1988. The effects of salt stress on polypeptides in membrane fractions from barley roots. Plant Physiology, 88: 1263-1273.

14. Ifuku, K., S. Ishihara, R. Shimamoto, K. Ido and F. Sato. 2008. Structure, function, and evolution of the $P s b P$ protein family in higher plants. Photosynthesis Research, 98: 427-437.

15. Kamal, A.H.M., K-H. Kim, K-H. Shin, J-S. Choi, B-K. Baik, H. Tsujimoto, H.Y. Heo, C-S. Park and S-H. Woo. 2010. Abiotic stress responsive proteins of wheat grain determined using proteomics technique. Australian Journal of Crop Science, 4: 196-208.

16. Kausar, R., M. Arshad, A. Shahzad and S. Komatsu. 2013. Proteomics analysis of sensitive and tolerant barley genotypes under drought stress. Amino Acids, 44: 345-359.

17. Komatsu, S. 2006. Plant proteomics databases: Their status in 2005. Current Bioinformatics, 1: 33-36.

18. Lepedu, H., A. Toma, S.A. Juri, Z. Katani, V. Cesar and H. Fulgosi. 2009. Photochemistry of PSII in CYP38 Arabidopsis thaliana. Food Technology and Biotechnology, 47(3): 275-280.

19. Macdonald, F.D. and B.B. Buchanan. 1997. The reductive pentose phosphate pathway and its regulation. In: Dennis, D.T., D.H. Turpin, D.D. Lefebvre and D.B. Layzell. (Eds.), Plant Metabolism (2nd ed., pp. 299-313). Essex: Addison Wesley Longman.

20. Morant-Manceau, A., E. Pradier and G. Tremblin. 2004. Osmotic adjustment, gas exchanges and chlorophyll fluorescence of a hexaploid triticale and its parental species salt stress. Journal of Plant Physiology, 169: 25-33.

21. Mushtaq, R., S. Katiyar and J. Bennett. 2008. Proteomic analysis of drought stress-responsive proteins in rice endosperm affecting grain quality. Journal of Crop Science and Biotechnology, 11: 227-232.

22. Naghavi, M.R. 2014. .Evaluation of spring wheat cultivars under drought stress and proteome analysis for the most tolerant and sensitive ones. PhD Thesis in Plant Breeding (Biometrical Genetics). Department of Plant Breeding and Biotechnology. Faculty of Agriculture. University of Tabriz, Iran. (In Persian).

23. Ng, J.H. and L.L. Ilag. 2002. Functional proteomics: separating the substance from the hype. Drug Discovery Today, 7: 504-505.

24. Nozu, Y., A. Tsugita and K. Kamijo. 2006. Proteomic analysis of rice leaf, stem and root tissues during growth course. Proteomics, 6: 3665-3670. 
25. Porubleva, L., K. Vander Velden, S. Kothari, D.J. Oliver and P.R. Chitnis. 2001. The proteome of maize leaves: use of gene sequences and expressed sequence tag data for identification of proteins with peptide mass fingerprints. Electrophoresis, 22: 1724-1738.

26. Rampino, P., S. Pataleo, C. Gerardi, G. Mita and C. Perrotta. 2006. Drought stress response in wheat: physiological and molecular analysis of resistant and sensitive genotypes. Plant, Cell and Environment, 29: 2143-2152.

27. Santos, C., A. Pereira, S. Pereira and J. Teixeira. 2004. Regulation of glutamine synthetase expression in sunflower cells exposed to salt and osmotic stress. Scientia Horticulturae, 103: 101-111.

28. Spreitzer, R.J. and M.E. Salvucci. 2002. Rubisco: structure, regulatory interactions, and possibilities for a better enzyme. Annual Review of Plant Biology, 53: 449-475.

29. Takahashi, S. and N. Murata. 2008. How do environmental stresses accelerate photo inhibition? Trends Plant Science, 13: 178-182.

30. Tamoi, M., M. Nagaoka, Y. Yabuta and S. Shigeoka. 2005. Carbon metabolism in the Calvin cycle. Plant Biotechnology, 22: 355-360.

31. van Wijk, K.J. 2001. Challenges and prospects of plant proteomics. Plant Physiology, 126: 501-508.

32. Wang, W., B. Vinocur, O. Soseyov and A. Altman. 2004. Role of plant heat-shock proteins and molecular chaperones in the abiotic stress response. Trends Plant Sciences, 9: 244-52.

33. Zang, X. and S. Komatsu. 2007. A proteomic approach for identifying osmotic-stress-related proteins in rice. Phytochemical, 68: 426-437.

34.Zivy, M. 1987. Genetic variability for heat shock proteins in common wheat. Theoretical Applied Genetics, 74: 209-213. 


\title{
Evaluation of Protein Pattern and Tolerance Mechanism in Two Cultivars of Wheat under Drought Stress in Seedling Stage
}

\begin{abstract}
In order to assess the protein pattern changes in tolerant and susceptible cultivars of wheat under drought stress in seedling stage and for understanding their mechanism of stress tolerance, two cultivars of spring wheat, including Kavir (as tolerant) and Bahar (as susceptible) were cultured in the growth chamber. Proteome analysis by 2D electrophoresis and staining of gels by Commassie brilliant blue for two cultivars was performed and 20 and 86 protein spots with significant difference between control and drought condition in the Kavir and Bahar cultivars were identified, respectively. Using MALDI-TOF/TOF, 18 and 84 protein spots of them in the Kavir and Bahar was identified. Total of proteins with significant expression changes related to the Kavir were divided into six functional groups, including Calvin cycle (seven protein spots), light reaction of photosynthesis (four spots), nitrogen assimilation and proton transfer (each two spots), the biosynthesis of starch and glycolysis (each one spot) and the unknown proteins (three spots). The number of protein functional groups in the Bahar was more diversity and these proteins were divided into 11 functional groups, while in Bahar as well as Kavir the highest numbers of proteins was related to the Calvin cycle (35 protein spots), light reaction of photosynthesis (22 spots), assimilation of nitrogen (eight spots) and proton transfer (five spots). Generally, the most protein amounts in the Kavir were related to Calvin cycle such as Fructose-bisphosphate aldolase (three spots) and $\mathrm{RuBisCO}$ small subunit precursor (two spots), respectively. While more of proteins involved in the Calvin cycle of Bahar cultivar such as RuBisCO activase A proteins (seven spots), fructose 1, 6-biphosphate aldolase (six spots) and catalytic large subunit of RuBisCO (five spots) were. On the other hand, in Bahar, proteins of OEC (12 spots) were the largest of protein groups involved in light reaction of photosynthesis. While in the Kavir, Cytochrome b6-f complex, Chlorophyll a-b binding protein, CYP38 and HCF136 protein under drought stress just one of each apiece were induced. Also in the Kavir and Bahar, the largest of protein groups related to nitrogen assimilation were Glutamine synthetase (GS) enzyme. Generally, these results to identify and better understand of the metabolic pathways, effective proteins and important proteins involved in tolerance and sensitivity of wheat will help.
\end{abstract}

Keywords: Drought Stress, Proteomics, Vegetative stage, Wheat 